University of Rhode Island

DigitalCommons@URI

Open Access Master's Theses

2019

\title{
ALONG-STREAM AND TEMPORAL VARIABILITY IN THE WEST GREENLAND CURRENT SYSTEM
}

Emma Jane Thomas

University of Rhode Island, emthomasj@gmail.com

Follow this and additional works at: https://digitalcommons.uri.edu/theses

\section{Recommended Citation}

Thomas, Emma Jane, "ALONG-STREAM AND TEMPORAL VARIABILITY IN THE WEST GREENLAND CURRENT SYSTEM" (2019). Open Access Master's Theses. Paper 1486.

https://digitalcommons.uri.edu/theses/1486

This Thesis is brought to you for free and open access by DigitalCommons@URI. It has been accepted for inclusion in Open Access Master's Theses by an authorized administrator of DigitalCommons@URI. For more information, please contact digitalcommons-group@uri.edu. 


\section{ALONG-STREAM AND TEMPORAL VARIABILITY IN THE WEST GREENLAND CURRENT SYSTEM \\ BY \\ EMMA JANE THOMAS}

A THESIS SUBMITTED IN PARTIAL FULFILLMENT OF THE REQUIREMENTS FOR THE DEGREE OF MASTER OF SCIENCE

IN

OCEANOGRAPHY

UNIVERSITY OF RHODE ISLAND 


\section{MASTER OF SCIENCE THESIS \\ $\mathrm{OF}$}

EMMA JANE THOMAS

APPROVED:

Thesis Committee:

Major Professor Kathleen Donohue

H. Thomas Rossby

Jason Dahl

Nasser H. Zawia

DEAN OF THE GRADUATE SCHOOL

UNIVERSITY OF RHODE ISLAND

2019 


\section{ABSTRACT}

The West Greenland Current System (WGCS) is a narrow boundary current which enters the Labrador Sea from the southeast and flows northward along the west Greenland coast. As part of the cyclonic circulation within the basin, it has recently received attention due to its contribution to Labrador Sea Water (LSW), having been observed with surface drifters, satellite altimetry, and synoptic hydrographic measurements. Direct velocity measurements, especially in the winter months, have been sparse, and there are few previous papers that look at the continuity between the East and West Greenland Current Systems. Additionally, while evidence has been found for a correlation between Labrador Sea processes and North Atlantic Oscillation (NAO), it is still unclear whether this correlation extends to current strength and if so whether it is the same correlation found east of Greenland.

This study makes use of an acoustic Doppler current profiler (ADCP) mounted on the hull of the container ship Nuka Arctica. Every three weeks, the ship crosses between Denmark and Greenland via the Irminger Sea before rounding Cape Farewell and continuing north along the Greenland coast. Two ADCP systems have operated: a $150 \mathrm{kHz}$ ADCP providing measurements to $400 \mathrm{~m}$ depth from 1999-2002, and a $75 \mathrm{kHz}$ ADCP providing measurements to $800 \mathrm{~m}$ depth from 2012-2016. During these periods, there were two years with a negative winter NAO and three to four years of wintertime measurements. Here, transport and velocities down to 400 meters depth are compared at six cross sections including one in the EGCS. Transport in the WGCS is found to be up to 1.6 Sv lower than in the EGCS, indicating deflection off of Eirik Ridge. Winter transport is generally higher than summer with a more pronounced difference in the EGCS. Similarly, with a 6-18 month lag, a negative NAO phase corresponds to a lower transport in the EGCS. The relationship between the NAO and the WGCS is not clear. 


\section{ACKNOWLEDGEMENTS}

I am grateful to my advisor Kathy Donohue for always having patience and pointing me in the right direction; this thesis would not have been completed without her insights and guidance. I would also like to thank Tom Rossby for providing the detided Nuka Arctica dataset as well as contributing a valuable perspective as a committee member. I am further indebted to S. Fontana for her work processing the data. Thank you to Jason Dahl for serving as a committee member, and to Reza Hashemi for serving as the committee chairperson. I am grateful to Karen Tracy for her knowledge, support, and being a wonderful person to share an office with. Lastly, thank you to all of the students and professors who made my experiences as a teaching assistant both enjoyable and educational, and to my family for always encouraging and supporting me. 


\section{PREFACE}

Rather than using the traditional division of the thesis into chapters, this thesis is written in "manuscript" style. The main text is written in a manner appropriate for submission to a scientific journal. 


\section{TABLE OF CONTENTS}

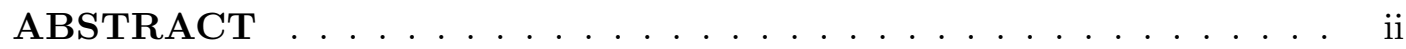

ACKNOWLEDGEMENTS .................. . . iii

PREFACE ...................... iv

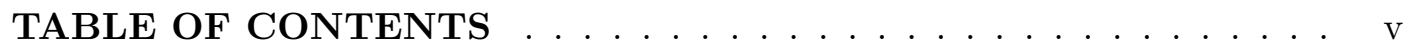

LIST OF TABLES ..................... . . . . . . . . . .

LIST OF FIGURES . . . . . . . . . . . . . . . . viii

MANUSCRIPT 1 Along-stream and temporal variability in the West

Greenland Current System . . . . . . . . . . . . . . . . 1

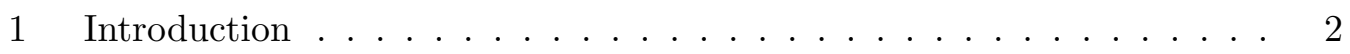

1.1 Structure of the current system . . . . . . . . . . . 2

1.2 Seasonality ....................... 4

1.3 Interannual variability . . . . . . . . . . . . . 5

1.4 Nuka Arctica ADCP data set . . . . . . . . . . . . 6

2 Methodology \& Procedures . . . . . . . . . . . . . . 8

2.1 Description of the data . . . . . . . . . . 8

$2.2 \quad$ Horizontal Gridding . . . . . . . . . . . . . . . . . . . 9

$2.3 \quad$ Cross-sections . . . . . . . . . . . . . . . . 9

2.4 Transport . . . . . . . . . . . . . . . 10

2.5 Seasonality . . . . . . . . . . . . . . 11

2.6 Variability between datasets . . . . . . . . . . . . . 12

2.7 North Atlantic Oscillation . . . . . . . . . . . . . . 12

2.8 Uncertainty/Error . . . . . . . . . . . . . . . . . 13

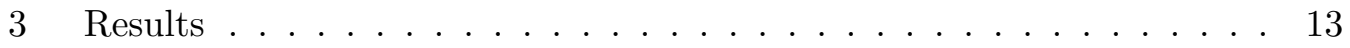

3.1 Mean velocity structure . . . . . . . . . . . . 13 
3.2 Mean volume transport . . . . . . . . . . . . . . 15

3.3 Seasonality . . . . . . . . . . . . . . 15

3.4 Variability between datasets . . . . . . . . . . . . . 17

3.5 North Atlantic Oscillation . . . . . . . . . . . . . 17

4 Further discussion . . . . . . . . . . . . . . . . . 18

4.1 Transport continuity . . . . . . . . . . . . 18

4.2 Coastal Current . . . . . . . . . . . . . . . . 19

4.3 Seasonality ......................... 20

4.4 North Atlantic Oscillation . . . . . . . . . . . . . . . 21

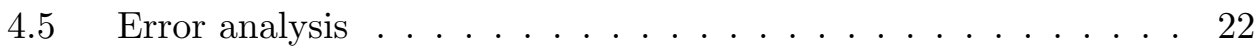

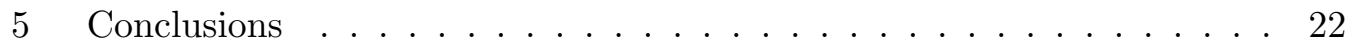

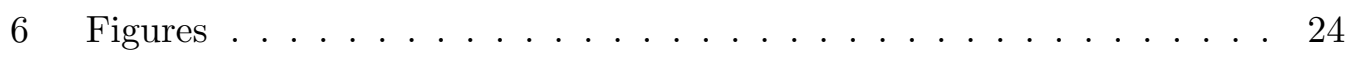

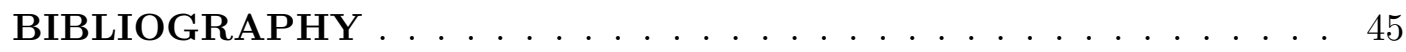




\section{LIST OF TABLES}

1.1 All transports . . . . . . . . . . . . . . . . . . . 16 


\section{LIST OF FIGURES}

1.1 Bathymetry and sea surface height mean and variance . . . . . . . . . . . 24

1.2 Tracks of the Nuka Arctica coded by ADCP instrument . . . . . . . . . 25

1.3 Tracks of the Nuka Arctica coded by season . . . . . . . . . . . . . . 26

1.4 Example of effective distance binning scheme . . . . . . . . . . . . . . 27

1.5 Example of the section binning scheme . . . . . . . . . . . 27

1.6 Map of gridded, depth-averaged velocities . . . . . . . . . . . . . . 28

1.7 Depth-averaged velocities by section with bathymetry . . . . . . . . 29

1.8 Contours of along-stream velocity at each section . . . . . . . . . . 30

1.9 Degrees of freedom in each bin at each section . . . . . . . . . . . . 31

1.10 Total transport . . . . . . . . . . . . . . . . . 32

1.11 Cumulative transport $\ldots \ldots \ldots \ldots$. . . . . . . . . . . . . . . . . . .

1.12 Total transport, summer and winter . . . . . . . . . . . . . . . 34

1.13 Cumulative transport, summer and winter . . . . . . . . . . . 35

1.14 Depth-averaged velocities by section, summer and winter . . . . . . . 36

1.15 Total transport, $1999-2002$ and $2012-2016 \ldots \ldots$. . . . . . . 37

1.16 Cumulative transport, $1999-2002$ and $2012-2016 \ldots \ldots$. . . . . . . . 38

1.17 Depth-averaged velocities by section, 1999-2002 and 2012-2016 . . . . . 39

1.18 Total transport, positive and negative $\mathrm{NAO} \ldots \ldots$. . . . . . . . . 40

1.19 Cumulative transport, positive and negative NAO . . . . . . . . . . . 41

1.20 Depth-averaged velocities by section, positive and negative NAO . . . . . 42

$1.21 \mathrm{NAO}$ and sea surface height gradient time series $\ldots \ldots \ldots$. . . . . . . 43

1.22 Seasonality and sea surface height gradient time series . . . . . . . . . . 44 
MANUSCRIPT 1

\section{Along-stream and temporal variability in the West Greenland Current System}

by

Emma J Thomas ${ }^{1}$ and Kathleen A. Donohue ${ }^{1}$

formatted for submission to the Journal of Geophysical Research - Oceans

\footnotetext{
${ }^{1}$ Graduate School of Oceanography, University of Rhode Island, Narragansett, Rhode Island, USA. Corresponding author: emthomasj@gmail.com
} 


\section{Introduction}

The West Greenland Current System (WGCS) is part of a larger system of cyclonic circulation around the Labrador Sea and the Atlantic subpolar gyre. The Labrador Sea and its associated current systems are of interest due to their effect on circulation and water properties across the North Atlantic, including the formation of Labrador Sea Water (LSW). Previous studies show that the WGCS provides important source waters to the interior of the Labrador Sea that are ultimately transformed into LSW (Kawasaki and Hasumi, 2014; Cuny et al., 2002), including Irminger Water (IW) via the Irminger Current. LSW, a convectively formed water mass, has been shown to carry climate signals equatorward (Curry et al., 1998); such far-reaching pathways mean that variation in its formation could have global impacts. Specifically, recent model studies have indicated that the Labrador Sea's role as a deep water formation site may decline dramatically as a result of climate change, with other locations in the northern Nordic Seas becoming proportionally more important (Lique and Thomas, 2018). A detailed, observation-based understanding of how source waters are transported into the basin and how they vary both seasonally and interannually is a vital part of understanding the effects and mechanisms of such changes. This study takes advantage of direct velocity measurements from an acoustic Doppler current profiler (ADCP) mounted on the hull of the container

ship Nuka Arctica, that regularly samples the WGCS, to answer outstanding questions about the current system, focusing on continuity between the east and west side of Cape Farewell and temporal variability due to seasons and North Atlantic Oscillation. The region of interest and the sections studied here are shown in Figure 1.1.

\subsection{Structure of the current system}

The West Greenland Current (WGC) and Irminger Current (IC) flow along nearly the same path and are distinguished by temperature and density differences rather than velocity. Both round Cape Farewell and follow the Greenland coast northward, but the WGC is recognized as the colder and fresher flow at the surface and nearer the coast 
while the IC is a warmer and saltier flow below the surface and slightly offshore (Rykova et al., 2015; Cuny et al., 2002; Kawasaki and Hasumi, 2014). Because the two currents are defined by water mass properties rather than velocity, "West Greenland Current System" is used to refer to both. However, south and east of Cape Farewell, the upstream system is known to comprise the East Greenland Coastal Current (EGCC), the offshore East Greenland Current (EGC), and the eastern leg of the IC. The coastal current has transports in the neighborhood of $1-2 \mathrm{~Sv}\left(1 \mathrm{~Sv}=10^{6} \mathrm{~m}^{3} \mathrm{~s}^{-1}\right)$ and peak velocities of 0.7 $0.81 \mathrm{~m} / \mathrm{s}$ (Sutherland and Pickart, 2008; Lin et al., 2018). While the coastal current may be defined in terms of density and salinity based on assumptions about its source waters, it is also possible to define it using only velocity: both and Sutherland and Pickart (2008) and Lin et al. (2018) define $15 \%$ of the peak velocity as the boundary between the EGC and the EGCC (Bacon et al., 2002; Sutherland and Pickart, 2008; Lin et al., 2018). The two distinct velocity maxima have been thought to merge shortly after Cape Farewell (Cuny et al., 2002; Holliday et al., 2007), although Lin et al. (2018) finds evidence of a coastal current in the WGCS as far as $60^{\circ} \mathrm{N}$ which may have been missed in previous studies due to limited near-shore, shallow water observations. For simplicity, and due to inconsistent findings regarding the EGCC, the current system east of Cape Farewell will also be referred to as the "East Greenland Current System" or EGCS.

In addition to the coastal current, Holliday et al. (2007) observe possible deflection/retroflection near Eirik Ridge. Significant offshore recirculation is also observed both east and west of Cape Farewell, occurring in the form of several distinct, closed recirculation cells on the Greenland and Labrador coasts according to Lavender et al. (2005). These recirculations are described by Fratantoni and Pickart (2007) as a variable, short-term phenomenon, typically not present in coarsely gridded data or long-term averages. Similarly, smaller scale $(10$ to $50 \mathrm{~km}$ ) eddies of varying lifespans arise from both baroclinic and barotropic instability (Kawasaki and Hasumi, 2014), including "Irminger Rings," "Boundary Current Eddies" and "Convective Eddies" (Chanut et al., 2008) and are thought to play a large role in mixing water mass properties between the boundary 
currents and the interior Labrador Sea, thereby influencing convection and downwelling processes (Georgiou et al., 2019).

The WGCS has been shown to be very barotropic at the AR7W section, with velocities as high as 10-20 cm/s extending $3000 \mathrm{~m}$ to the sea floor (Hall et al., 2013). This significant barotropic component is reflected in the fact that estimates derived from thermal wind/geostrophy consistently underestimate current speeds compared to direct measurements. Rykova et al. (2015) and Fratantoni and Pickart (2007) both present velocities in the WGC that only just exceed $0.30 \mathrm{~m} / \mathrm{s}$, though direct velocity measurements of the E/WGCS are often greater than $0.5 \mathrm{~m} / \mathrm{s}$ (Holliday et al., 2009; Hall et al., 2013; Rossby et al., 2017; Lin et al., 2018). Transports have been assumed to be consistent along the length of the WGCS, due to limited available data (Schmidt and Send, 2007). However, due to the exchange with the interior Labrador Sea and previously observed recirculation, retroflection, and a lack of studies on the continuity between the East and West Greenland Current systems, these aspects warrants further investigation.

\subsection{Seasonality}

Seasonal signals have been observed in both the EGCS and WGCS, but direct wintertime measurements, especially in the WGCS, have been limited. From altimetry, Daniault et al. (2011) find a seasonal transport cycle in the EGC with an amplitude of $1.8 \mathrm{~Sv}$, hitting a maximum in January and a minimum in July. They also note that altimetry has a lower standard deviation than direct mooring measurements over the same period of time, indicating that the actual seasonal variation may be more dramatic than the altimetry result. Similarly, Bacon et al. (2014) use an observationally-validated model and find a February maximum transport in the EGCC. Offshore of the WGCS, there is a well-known eddy kinetic energy maximum that shows highest variability in winter. Prater (2002) sees maximum variability during January to March, and hypothesizes that this arises from seasonal variations in the strength of the WGCS. White and Heywood 
(1995) find the same eddy kinetic energy hotspots and seasonal cycle, but distinguish between variations caused by wind stress alone as compared to variations due to the strength of nearby currents and resulting baroclinic instabilities. The WGCS is known to shed eddies due to baroclinic instabilities (Chanut et al., 2008), and despite the lack of observations, there is direct evidence of a seasonal signal in the WGCS that could indeed be driving the eddy kinetic energy cycle: velocities are significantly higher in the fall (October through December) and winter (October through February), mostly due to the baroclinic component (Rykova et al., 2015; De Jong et al., 2016). Although there are confirmed seasonal signals both east and west of Cape Farewell, there are few studies that look at the continuity of such signals between the EGCS and WGCS, and limited direct measurements of seasonal velocity signals in the WGCS.

\subsection{Interannual variability}

Rykova et al. (2015) examined summer geostrophic surface velocities between 1994 and 2008 at AR7W using satellite altimetry, finding a decrease of at most $0.1 \mathrm{~m} / \mathrm{s}$ in a lowpass mean. This is much smaller than the overall variability (see their figure 8), and a 2005-2008 increase may suggest a possible return to 1994-2000 values rather than a continuous decrease. In the EGCS, transport does not change significantly between 19992002 and 2012-2016, the two intervals looked at here (Rossby et al., 2017). Combining data from the two intervals should be a reasonable representation of a mean state.

Previous evidence indicates that the positive phase of the North Atlantic Oscillation (NAO) corresponds to a strengthened WGCS. A warmer Labrador Sea, typically present during low-NAO periods, indicates slower overall circulation (Häkkinen and Rhines, 2004). High eddy kinetic energy (Zhang and Yan, 2018) and increased LSW formation (Yashayaev and Loder, 2016) are both observed during high NAO periods, both of which are associated with instabilities arising from stronger current speeds (Prater, 2002; Chanut et al., 2008).

In the past, the region's response to NAO has mostly been studied in terms of 
long-term averages. Sarafanov et al. (2012), for instance, use a 7-year mean to define 2002-2008 as a period of "neutral" NAO despite a range of individual yearly values. During the 1990s the Labrador Sea experienced a decrease in circulation corresponding with a long period (at least 5 years) of high NAO early in the decade, contrasting with low-to-neutral NAO after 1995 (Häkkinen and Rhines, 2004). Similar studies of the EGCS compare the early 1990s to 1995-1998 (Flatau et al., 2003) and 2001-2005 (Våge et al., 2011). Both observed a decrease in EGCS surface currents, but the former finds no change in the WGCS, and the latter only looks at the Irminger Gyre.

The significance of short-term fluctuations in the NAO, and the continuity across the east and west current systems is thus inconsistently studied and poorly understood. During individual 1-2 year periods, NAO indices and current strength or variability may appear to correlate or anti-correlate, depending on the year (Cuny et al., 2002). Additionally, it is unclear whether a lag time exists between NAO signals and a response in the WGCS, and if so how long it may be. Although the studies above consider NAO values concurrent with observations, Myers et al. (2007) assert that LSW formation responds to IW transport around Cape Farewell, and IW transport is correlated to NAO, with a lag of 1 year. On the other hand, the lag time between wind stress and EKE in the Labrador Sea is likely less than 1 month (Brandt et al., 2004). Since eddy activity responds to both wind stress and current strength (White and Heywood, 1995), the observed NAO-correlated changes in LSW formation and deep convection seem to be affected by multiple processes with varying lag times with respect to NAO. It is therefore unclear whether the WGCS responds almost immediately to NAO-induced wind stress changes, or if the apparent lag in Cape Farewell IW transport is an indication of a slower response.

\subsection{Nuka Arctica ADCP data set}

The studies referenced above use a variety of instrumentation including surface drifters and profiling floats, satellite altimetry, hydrographic surveys, current meter moorings, 
and lowered ADCP sections. Many of these methods lack coverage spatially and/or temporally. Hydrographic sections are often synoptic, providing only a snapshot view of the system; repeated observations such as moorings or repeat hydrographic surveys are limited to a few locations and are less useful for investigating continuity. Floats and drifters provide data over large distances, and yet are limited to specific depth horizons and are often unable to observe shallow coastal currents. Satellite altimetry provides large-to-mesoscale multi-year observations but cannot resolve narrow boundary currents nor can it provide information below the surface. Although it has its own challenges, many of the above issues are avoided with the Nuka Arctica ADCP data set.

The Nuka Arctica travels between Denmark and Greenland on a 3-week schedule, crossing the Irminger Sea before rounding Cape Farewell and continuing north parallel to the West Greenland coast (Figs. 2 and 3). The direction of the Nuka Arctica's travel coincides roughly with the WGCS, but because there is considerable variation in the exact path of the ship between trips, the tracks provide comprehensive horizontal coverage. Thus the ADCP is able to provide information about the along-stream structure of the current system. The Nuka Arctica data set also measures velocity as a function of depth at each data point, including waters much shallower than the typical 1000 or $2000 \mathrm{~m}$ parking depth of profiling floats. Finally, since the Nuka Arctica makes trips year-round, it is able to resolve seasonal variability, which has been a challenge in studies that make use of moorings or hydrographic surveys. Here, ADCP measurements from two Nuka Arctica data sets spanning 1999-2002 and 2012-2016 are analyzed in the context of the topics above.

Specific questions that will be addressed include whether there is a transport loss over Eirik Ridge, supporting the existence of diverted flow as seen in Holliday et al. (2007), and how far downstream the coastal current persists. Transport and velocities of the two data collection intervals will also be compared to look for long term trends.

As discussed above, there is evidence of the EGCS responding to North Atlantic Oscillation on timescales of 3-5 years, while a possible response of the WGCS is less 
studied and less clear: research that sees a change in the EGCS concurrent with changing NAO indices often do not study the WGCS or do not see a comparable change. Here, the response of both currents to short-term (1 year) negative NAO periods is tested, using a lag time of 6-18 months based on previously suggested lag times of relevant processes.

Finally, seasonality in the EGCS and WGCS will be tested. A cycle with higher transport in winter is expected in both, but the magnitude of the cycle and whether it s timing is consistent across both currents remains to be seen.

\section{Methodology \& Procedures}

\subsection{Description of the data}

The region investigated here extends from approximately $60^{\circ} \mathrm{N} 42^{\circ} \mathrm{W}$, around Greenland's Cape Farewell, and north along the coast to nearly $64^{\circ} \mathrm{N}$; this includes a portion of the EGC and its associated pathways such as the eastern IC and the EGCC.

The data set is distributed between two intervals of data collection: 1999-2002 and 2012-2016. The earlier set used a $150 \mathrm{kHz}$ ADCP, providing measurements as deep as $400 \mathrm{~m}$ with a resolution of $8 \mathrm{~m}$; the second interval used a $75 \mathrm{kHz}$ ADCP reaching 800 $\mathrm{m}$ with a resolution of $16 \mathrm{~m}$. The earlier data set is lacking in wintertime data, but the 2012-2016 set includes a full year-round distribution. The distribution is mapped in Figure 1.2 and Figure 1.3.

Combining the two data sets is a challenge due to the differing depth intervals. Rather than interpolate the coarser 2012-2016 data onto a finer grid and risk representing a finer resolution than was measured, the 1999-2002 set with 8 meter resolution is linearly interpolated onto the depth planes observed in 2012-2016. The result is a single data set, extending from 31 to $800 \mathrm{~m}$ with 16 meter intervals. However, coverage is patchy below the 1999-2002 depth cutoff, so all analyses were limited to observations at $400 \mathrm{~m}$ or shallower.

Velocity data have been detided as in Rossby et al. (2017) and Chafik et al. (2014), in which the spatial dependence of the principal tidal components in the upper $100 \mathrm{~m}$ 
were calculated using a least square method (Wang et al., 2004).

\section{$2.2 \quad$ Horizontal Gridding}

A grid with $0.4^{\circ}$ longitude $\times 0.2^{\circ}$ latitude resolution is defined so as to produce a comprehensive map of the full system that complements the cross-sections discussed below. To create this map, each data point is assigned to the closest grid point. The definition of "closest" is adjusted to account for correlation scales that are longer along topography than across topography. Instead of using physical distance, "effective distance" as used in Lavender et al. (2005) may be calculated instead:

$$
D_{\text {eff }}^{2}=D^{2}+\left(3 \lambda \frac{H_{g}-H_{d}}{H_{g}+H_{d}}\right)^{2}
$$

where $D$ is the physical distance, $\lambda$ is a specified coefficient, $H_{g}$ is the water depth at the grid point and $H_{d}$ is the water depth at the data point. Thus a data point is effectively "farther" from a grid point if the bathymetry in between is particularly steep. We are therefore assuming that the current is mainly along isobaths to avoid averaging data from different parts of the current. Here $\lambda=100 \mathrm{~km}$, and depths are interpolated from Smith and Sandwell (1997) satellite bathymetry. Figure 1.4 visualizes how using effective distance affects the shape of the bins surrounding the grid points.

\subsection{Cross-sections}

Multiple 2-dimensional cross-sections of the E/WGCS are analyzed. Each section's final position is refined to be perpendicular to the mean flow direction, with coordinates determined by choosing endpoints in the approximate region of interest, calculating depth-averaged (over $100 \mathrm{~m}$ ) velocities, and defining a new endpoint that produces a section perpendicular to the maximum velocity.

Section locations are visualized in Figure 1.1 and were chosen based on bathymetry, previous studies, and data coverage. Section A is similar to the EGC section studied in Rossby et al. (2017), though its angle has been slightly adjusted consistent with the

method described above (while Rossby et al. positioned the section perpendicular to 
bathymetry). This section is valuable as an upstream reference to which downstream continuity may be compared, and for verifying that the results are comparable to previous studies. Sections $\mathrm{B}_{1}$ and $\mathrm{B}_{2}$, together making up Section $\mathrm{B}$, are placed upstream of Eirik Ridge and are motivated by the unique bathymetry of the ridge combined with the sharp turn in the path of the current system. Section $\mathrm{C}$ is placed immediately downstream of the ridge for the same reason. Section D is placed to coincide with the AR7W line, the focus of multiple previous studies and therefore useful for comparisons. As with Section A, its angle has been adjusted to be perpendicular to the mean current flow observed in the Nuka Arctica data. Section E is placed just downstream of a patch of high sea surface height variability near the coast. Section F is placed slightly farther north to capture flow closer to the separation of the 3000 meter isobath. Section lengths, measured from the outside bin edges, are as follows: $140 \mathrm{~km}(\mathrm{~A}), 240 \mathrm{~km}(\mathrm{~B}), 180 \mathrm{~km}(\mathrm{C}), 110 \mathrm{~km}(\mathrm{D})$, $130 \mathrm{~km}(\mathrm{E})$ and $150 \mathrm{~km}(\mathrm{~F})$.

To calculate velocities, each section is divided into bins $10 \mathrm{~km}$ wide in the acrosscurrent direction and extending $15 \mathrm{~km}$ upstream and downstream (Figure 1.5). Note that this averaging scheme differs from the one used to construct the mapped field yet both approaches allow for longer bins in the along-stream direction compared with the across-stream direction. The mean of all data points within a given bin is assigned to the center of that bin. This applies both horizontally and vertically, so observations located on the $399 \mathrm{~m}$ depth plane, for example, are taken to represent the 391 to $407 \mathrm{~m}(399 \pm 8)$ depth interval. Transport estimates are explicitly calculated from 31 to $399 \mathrm{~m}$, with the surface layer approximated by extending the $31 \mathrm{~m}$ values vertically to $0 \mathrm{~m}$ depth.

\subsection{Transport}

Directly measured, full-depth transports are not possible with this data set. To combine the 1999-2002 and 2012-2016 data sets, all transport estimates are cut off at $400 \mathrm{~m}$ as discussed above.

Velocities are converted from a west-east versus south-north coordinate system to 
coordinates parallel and perpendicular to the cross-section. This is done by finding the angle, $\theta$, between the east versus north coordinate system and the section's coordinate system, then rotating all coordinates counterclockwise by this angle. The positive y-axis of the rotated coordinate system is consistently defined as pointing in the direction of mean current flow. If the original velocity components are $u$ (west-east) and $v$ (southnorth), then

$$
u^{\prime}+i v^{\prime}=(u+i v) e^{-i \theta}
$$

Where $u^{\prime}$ is the component parallel to the section pointing towards the Greenland coast, and $v^{\prime}$ is perpendicular to the section and parallel with the primary flow direction. Transport is then given by

$$
\sum(\Delta z)(\Delta x)\left(v^{\prime}\right)
$$

where $\Delta z$ is the vertical grid resolution of the data $(16 \mathrm{~m})$ and $\Delta x$ is the bin width (10 $\mathrm{km}$ ). Measurements start at $31 \mathrm{~m}$ depth, and the mean at each point is considered the center of its box in both distance and depth. This leaves a $23 \mathrm{~m}$ deep top layer unaccounted for, which is assigned the shallowest measured velocities. Transport estimates thus represent the top $407 \mathrm{~m}$ in deep water and extend to the deepest measurement in shallow water. For comparisons between time periods, shallow-water velocities were cut off at the deepest common depth plane; for example, if wintertime measurements in a shallow bin extend to $95 \mathrm{~m}$ while summer extend to $159 \mathrm{~m}$, the summer velocities are truncated at 95 to keep the area consistent between calculations.

\subsection{Seasonality}

Winter is defined as October through March and summer is defined as April through September. This is loosely based on the seasons used in Rykova et al. (2015), who defined winter as October through February and summer as May through July. In other studies of the region such as Prater (2002), March is commonly included in the winter season, and was included here to facilitate more thorough data coverage than the 5-month Rykova winter would allow. Similarly, the remaining months (April through 
September) are defined as summer rather than the 3-month May-July season. These definitions allow for more complete data coverage and are consistent with the two-season cycle accepted by previous research. However, they do not allow for the construction of a detailed seasonal cycle with specific months of minimum or maximum transport.

Because the seasonal comparison results in sparser data coverage, it was necessary to adjust the endpoints of sections to avoid gaps due to empty bins. Specifically, Sections B, C, and E were all shortened slightly, from 240 to $190 \mathrm{~km}, 180$ to $150 \mathrm{~km}$, and 130 to $100 \mathrm{~km}$. Section $\mathrm{F}$ is left out completely. Interestingly, winter cross-sections show negative velocities further inshore than summer cross-sections, possibly indicating that the full current is captured despite the shortened section lengths. Whether this is due to a narrowing of the current structure in winter, or if it represents short-term eddying and re-circulation that is lost in broader averages, is unclear. Regardless, sea-surface height contours (not shown) confirm that almost all sections still extend over the steepest part of the SSH gradient.

\subsection{Variability between datasets}

The two data-collection intervals are compared to look at longer-term variability. To ensure results are not affected by seasonal variation, only data collected between AprilSeptember are considered, because there is limited October-March coverage in the 19992002 time period. This limitation greatly reduces the data coverage so that only Sections A, B, and C may be reasonably looked at; endpoints are also adjusted such that Section B is shortened from $240 \mathrm{~km}$ to $180 \mathrm{~km}$, and Section C from $180 \mathrm{~km}$ to $120 \mathrm{~km}$.

\subsection{North Atlantic Oscillation}

Winter NAO Index Data is provided by the Climate Analysis Section, NCAR, Boulder, USA, Hurrell (2003). Two negative NAO years (2001 and 2003) are considered here (see Figure 1.21). To test a lag time of 6-18 months, a year starting in June and ending in May is defined such that data collected between June 2001-May 2002, for example, 
is associated with the December 2000-March 2001 negative NAO index. With some adjustments to endpoints, this distribution allows for every section to be looked at. Specifically, Sections B, C, E and F are shortened to $230 \mathrm{~km}, 170 \mathrm{~km}, 100 \mathrm{~km}$, and 110 $\mathrm{km}$ respectively (their original lengths being $240 \mathrm{~km}, 180 \mathrm{~km}, 130 \mathrm{~km}$, and $150 \mathrm{~km}$ ).

\subsection{Uncertainty/Error}

For the purpose of calculating standard error, one ship track contributes one degree of freedom to each bin it crosses. Thus the standard error of the mean formula is

$$
S E=\frac{\sigma}{\sqrt{D F}}
$$

where $\sigma=$ standard deviation and $D F=$ the number of ship tracks crossing the bin. This results in an error for each bin at every depth. To propagate this through the transport calculation, the following formula is used:

$$
\delta T=(\Delta z)(\Delta x) \sqrt{\sum(\delta v)^{2}}
$$

where $\delta T$ is the uncertainty on the transport and $\delta v$ is the standard error of the mean in each bin at each depth.

\section{Results}

\subsection{Mean velocity structure}

Figure 1.6 shows the gridded velocities averaged over the upper $100 \mathrm{~m}$ and provides a regional view of the near-surface circulation. Data coverage is good: in regions of strong flow the averaging bins have more than 3 degrees of freedom. Generally, the strong flows of the W/EGCS flow along isobaths. This is especially evident between $45^{\circ} \mathrm{W}$ and $48^{\circ} \mathrm{W}$ where mean velocities follow the bathymetry to turn sharply in a more westward direction. A small component of flow parallel to Eirik Ridge is visible, as well as a tendency for the current system to move slightly offshore as the WGCS flows north along the western side of Greenland. The coastal current is less apparent in 
this gridded map. In regions where the current system is strong, standard deviation ellipses generally align with the directions of the strongest velocities, i.e. variability tends to be in the along-isobath direction. Large amplitude variability, indicated by larger standard deviation ellipses, occurs near $47^{\circ} \mathrm{W}$ and is consistent with the pattern of elevated satellite-SSH variability (Figure 1.1). The velocity structure, both horizontal and vertical, may be looked at in more detail at specific sections (A through F) using near-surface vector plots (Figure 1.7) and across-section velocity contours as a function of distance and depth (Figures 1.8 and 1.9).

A coastal current is observed at Sections A, B, and C. The coastal current remains inshore of the $200 \mathrm{~m}$ isobath at all three of these sections, consistent with the results presented by Lin et al. (2018). How far past Section C the coastal current persists is unanswered, although in the gridded map (Figure 1.6), velocities on the order of 0.1$0.5 \mathrm{~m} / \mathrm{s}$ do appear inshore of the 200 meter isobath between Section C and Section D. Additionally, the westward shift of the current's direction near $60^{\circ} \mathrm{N}$ may represent the sharp westward direction of the coastal current observed by Lin et al. (2018) at their Section k8.

The shift of the current core with respect to the isobaths is also apparent in both depth-averaged vector plots and velocity contours. The offshore velocity peak of the main current occurs over shallower, 500-1500 m depths at Sections A and C versus 1500$2000 \mathrm{~m}$ depths at Section B and offshore of the $2500 \mathrm{~m}$ isobath at Sections D-F. The vector plots in particular reveal weak flow diverging from the coast at Section F.

Velocity contours (Figures 1.8 and 1.9) offer more insight into vertical structure and offshore flow behavior. As inferred from mean SSH contours (Figure 1.1), the sections capture the full width of the current system. Reversed offshore velocities are observed at all sections with the exception of Section A. Nevertheless, Section A shows very weak flows $(<.05 \mathrm{~m} / \mathrm{s})$ at the offshore limit, indicating that this section also encapsulates the full width. The offshore current is narrowest at Section A (about $30 \mathrm{~km}$ ), and broader at Section B where the current width is about $50 \mathrm{~km}$ and weak positive (downstream) 
velocities extend to $200 \mathrm{~km}$ offshore. Presumably, this is due to Section B's crossing Eirik Ridge. Section F also presents a relatively wide current although we note that it has relatively few degrees of freedom compared to other sections.

\subsection{Mean volume transport}

Transport estimates are listed in Table 1 and compared in Figure 1.10; cumulative transport is plotted in Figure 1.11. These estimates begin as close to the coast as data coverage allows, and extend offshore either to the end of the defined section, or to the maximum cumulative value. Therefore, offshore recirculations or flow reversals are excluded. Overlaying mean sea surface height as in Figure 1.1 confirms that each section provides coverage over the steepest SSH gradient in the region and can be understood to represent the entire width of the current. This is further confirmed by the leveling off of cumulative transport plots in Figure 1.11.

Transport decreases from Section A systematically through Section E from 11.8 $\mathrm{Sv}$ to $9.2 \mathrm{~Sv}$, respectively and represents a $22 \%$ decrease. The most dramatic decrease (13\% or $1.6 \mathrm{~Sv})$ occurs between Sections A and B. This decrease in transport is especially interesting in the context of Holliday et al. (2007), who observe partial retroflection of the current near Eirik Ridge. Their schematic depicts transport loss occurring directly over the ridge, west of $44^{\circ} \mathrm{W}$. Here, Section B provides evidence for diverted flow significantly upstream of the ridge. The subsequent decrease in transport from Section B through Section E indicates a more continuous loss. Transport increases to $11.0 \mathrm{~Sv}$ at Section F.

\subsection{Seasonality}

Transport estimated as a function of season are listed in Table 1 and compared in Figure 1.12; cumulative transport is plotted in Figure 1.13.

All sections except for $\mathrm{D}$ show a higher transport during winter. The difference is most extreme at Section A $(9.4 \pm 0.2 \mathrm{~Sv}$ in summer versus $13.6 \pm 0.2 \mathrm{~Sv}$ in winter), due entirely to much higher wintertime velocities: Sections A through D have nearly 


\begin{tabular}{||c||c|c|c|c|c|c||}
\hline Section: & $\mathrm{A}$ & $\mathrm{B}$ & $\mathrm{C}$ & $\mathrm{D}$ & $\mathrm{E}$ & $\mathrm{F}$ \\
\hline \hline Full-year & $11.8 \pm 0.1$ & $10.2 \pm 0.1$ & $9.8 \pm 0.2$ & $9.3 \pm 0.1$ & $9.2 \pm 0.3$ & $11.0 \pm 0.2$ \\
\hline \hline April-Sept. & $9.4 \pm 0.2$ & $9.2 \pm 0.1$ & $9.1 \pm 0.1$ & $9.3 \pm 0.1$ & $8.0 \pm 0.1$ & - \\
\hline Oct.-Mar. & $13.6 \pm 0.2$ & $9.8 \pm 0.3$ & $10.2 \pm 0.2$ & $9.1 \pm 0.2$ & $9.6 \pm 0.2$ & - \\
\hline \hline 1999-2002 & $7.7 \pm 0.2$ & $9.6 \pm 0.2$ & $8.5 \pm 0.2$ & - & - & - \\
\hline $\mathbf{2 0 1 2 - 2 0 1 6}$ & $9.6 \pm 0.2$ & $7.4 \pm 0.2$ & $9.0 \pm 0.2$ & - & - & - \\
\hline \hline NAO + & $12.0 \pm 0.1$ & $10.4 \pm 0.2$ & $9.2 \pm 0.2$ & $9.0 \pm 0.1$ & $8.3 \pm 0.2$ & $10.2 \pm 0.2$ \\
\hline NAO - & $11.0 \pm 0.2$ & $7.8 \pm 0.2$ & $9.2 \pm 0.2$ & $8.8 \pm 0.2$ & $8.0 \pm 0.4$ & $9.8 \pm 0.2$ \\
\hline
\end{tabular}

Table 1.1: Transports above $407 \mathrm{~m}$, at all sections and for all time periods examined. The horizontal extent of Sections B through $\mathrm{F}$ are truncated for most temporal comparisons due to data coverage and therefore values across categories (e.g. full mean versus positive NAO) should not be compared.

identical summer transports and the decrease in transport over the Eirik Ridge observed in the mean transports is only observed in the winter transports (from October through March).

We take a closer look at the seasonal differences at Section D due to its higher summer/lower winter transport. Cumulative transport at Section D reaches a maximum closer to shore during winter, with a reversed flow offshore that may represent short-term eddying processes. Inshore winter velocities at Section D are comparable to or higher than summer velocities.

Similarly, it should be noted that the summer data coverage at Section E extends further offshore than the winter data coverage, resulting in a maximum summer transport of $9.5 \pm 0.2 \mathrm{~Sv}$. The values in Table 1 for Section $\mathrm{E}$ therefore do not represent the full transport of the current, but instead compare seasonal transports between the same endpoints. Recall that the seasonal sections are slightly shorter than the full-mean sections.

High wintertime transport is consistent with the maxima in IC velocities found by Rykova et al. (2015) during October-February and October-December. It also agrees with observed sea surface height fluctuations and the January maximum transport reported by Daniault et al. (2011). However, Rykova et al. (2015) finds the shallow, coastal WGC to be slower in the winter with the bulk of the flow moving offshore to the deeper IC. 
This is not observed in the Nuka Arctica data, with even velocities closest to the coast increasing during winter.

\subsection{Variability between datasets}

Transport estimated during the 1992-2002 and 2012-2016 periods are listed in Table 1 and compared in Figure 1.15; cumulative transport is plotted in Figure 1.16. There is no consistent difference between 1999-2002 and 2012-2016 transports (Figure 1.15); 20122016 transports are higher at Sections A and C, but the opposite is true at Section B, where a strong reverse flow is observed closer to shore in 2012-2016. While this reverse flow is not directly subtracted from the total transport estimate, it does effectively narrow the current over which transport is calculated. Section B has much better data coverage in 1999-2002, and the reverse flow is entirely observed in bins that each contain less than 3 ship tracks, so it is possible that the negative flow is evidence of short term eddying or recirculation rather than a mean state.

Looking at velocity profiles of the current (Figure 1.17), all sections show increased spatial variation and a more defined coastal current in 2012-2016. The later period also has larger standard deviation ellipses, possibly indicating higher temporal variation. In contrast, 1999-2002 current maxima are not dramatically higher than neighboring bins and there is no coastal current observed. The question of whether the current system has trended towards higher spatial and temporal variability over short timescales may be further investigated with SSH gradients or other data sources.

\subsection{North Atlantic Oscillation}

Figures 1.18 and 1.19 show the transports computed for high and low NAO years. Recall that a low NAO year is defined as the June-May year following a negative DJFM NAO index. Winter NAO Index Data is provided by the Climate Analysis Section, NCAR, Boulder, USA, Hurrell (2003).

The response of the current differs between the EGCS and WGCS. Sections A 
and B show slightly higher transport following high/positive NAO years. This result is significant in that it shows a possible response of the EGCS to NAO fluctuations of only 1 year, when previous research has focused on longer-term averages. In the WGCS, both transport and horizontal current structure are nearly identical between high- and lowNAO years. This is consistent with previous research that finds no consistent correlation between NAO indices and SSH gradients (Prater, 2002). These results suggest that the WGCS may be less subject to direct NAO influence compared to the EGCS, at least during the time frames considered here.

We explored whether different lags might be considered in this analysis by examining the relationship between NAO and SSH gradients determined from satellite altimetry along several sections. Figure 1.21 shows the Winter NAO index from 1990 to 2016 overlaid by a 52 -week running mean of the difference in SSH-gradient anomaly across Section D. Here a positive anomaly represents a steeper gradient and therefore a stronger WGCS. No consistent relationship is apparent between NAO and SSH gradients.

\section{Further discussion}

\subsection{Transport continuity}

Up to $2.5 \mathrm{~Sv}$ is lost from the E/WGCS as it rounds Cape Farewell, some of which occurs upstream of the regions of transport loss observed by Holliday et al. (2007). There appears to be a gradual transport loss between Sections B to E. The initial drop may be evidence of the boundary between previously observed recirculation cells on either side of Cape Farewell (Spall and Pickart, 2003; Lavender et al., 2005). This loss is mostly recovered at Section $\mathrm{F}$ near $61^{\circ} \mathrm{N}$, which contradicts previous assumptions that transport is constant along the WGCS downstream of Cape Farewell (Schmidt and Send, 2007). Velocity contours indicate that the recovery is due to a shifting of maximum velocities offshore (and negligible vertical shear of these velocities); this is consistent with observations that the shallow, coastal WGC slows as it reaches higher latitudes (Cuny et al., 2002). 
Specifically, the current is centered roughly $50 \mathrm{~km}$ offshore of the shelf break at Section F, and velocities of up to $0.4 \mathrm{~m} / \mathrm{s}$ extend from the surface to the $400 \mathrm{~m}$ deep cutoff. Sections B and C also show little change in velocity with respect to depth, but the offshore current is considerably slower at these locations, where the highest velocities (up to $0.5 \mathrm{~m} / \mathrm{s}$ ) occur in water less than 200 meters deep. The zero-velocity contour also appears closer to the shelf break at Sections C, D, and E than at Section F, shortening the current width over which transport is calculated. The widening of the current combined with the shifting of velocity maxima into deeper water and little vertical velocity shear above $400 \mathrm{~m}$ are likely responsible for the increased transport at Section F. Since this section is close to regions of high eddy kinetic energy, it is unclear whether velocities are enhanced by eddy activity overlapping with the current, especially since data coverage at Section $\mathrm{F}$ is too sparse to investigate seasonally. Connections between EKE and current strength at Section F may be investigated in the future by combining the Nuka Arctica data set with a detailed time series of EKE obtained from satellite altimetry.

\subsection{Coastal Current}

The coastal current is not observed past Section C, and in 1999-2002 in particular it is hard to distinguish a coastal current at all, suggesting that it may be highly variable in strength. Although at least one previous definition of the EGCC uses only velocity (Lin et al., 2018), the definition used by Sutherland and Pickart (2008) includes the 34 psu isohaline as a depth boundary. The significantly fresher water of the coastal current has prompted speculation that it is a seasonal feature, intensified by summer glacial runoff (Bacon et al., 2002), but here we find stronger and more distinct coastal velocities in winter. Additionally, the similarity in the salinity-based definition of the EGCC and the 34.4 psu boundary between the WGC and IC used by Rykova et al. (2015) may suggest they are better viewed as two legs of the same pathway despite previous research treating the WGC as a continuation of the EGC, not the EGCC specifically (Schmidt and Send, 2007). The fact that the EGCC, like the WGC, is not always detected solely with veloc- 
ity data may support this perspective. Shallow, near-shore hydrography measurements at additional locations would be valuable in further determining the coastal current's relationship to seasonal meltwater as well as the continuity between it and downstream pathways.

\subsection{Seasonality}

The EGCS and WGCS are found to have a similar seasonal cycle: both are strongest October through March, although the seasonal transport difference in the EGCS is much greater (over $4 \mathrm{~Sv}$ in the EGCS versus up to $1.6 \mathrm{~Sv}$ in the WGCS).

Winter SSH gradient peaks are generally higher at Section A than at sections in the WGCS after 2007 (Figure 1.22). Even when the magnitude of the seasonal cycle is similar, however, the timing of the maximum SSH gradient is inconsistent: Section E consistently peaks earlier in the year than Section A. This means that while the seasonal definitions used above are an appropriate choice for Section A and the EGCS they are less useful at sections further along in the WGCS. At Section A, "winter" captures the steepest gradients or the peaks of the seasonal cycle, and "summer" captures the troughs of the cycle. At Section E, however, summer as defined here typically captures the ascent from minimum SSH steepness to maximum and winter represents the descent from maximum to minimum. Thus the larger seasonal difference in transport captured at Section A may not indicate that the WGCS has a lower-amplitude seasonal cycle, only that its cycle is often out-of-phase with the EGCS. Rykova et al. (2015) also found evidence for the WGCS reaching peak strength in the fall rather than winter. These findings seemingly contradict previous claims that variability in the WGCS is mostly due to wind forcing over the EGCS. Multiple definitions of seasons, perhaps even varying based on how far downstream each section is, may be considered for future studies assessing the amplitude of the WGCS seasonal cycle. This does raise further questions about current strength and nearby EKE, since earlier results indicate maximum EKE in the spring, rather than concurrent with the apparent maximum current strength in the 
fall.

\subsection{North Atlantic Oscillation}

The EGCS displays slightly lower transport 6-18 months following short-term negative wintertime NAO events, while the WGCS shows no measurable response over the same time periods. Differing responses of the two systems is somewhat expected. The SSH gradient at Section A does not correlate well with the gradient at Section D or E, while it does correlate better with Section B. The recirculation cells discussed above also demonstrate that while the EGCS is responsible for some forcing of the WGCS, they each make up part of two distinct, not fully connected systems. If the EGCS acts as a western boundary current, responding primarily to wind stress curl (while the WGCS responds to a wider variety of specific conditions), then its stronger response to both seasonal and NAO fluctuations would makes sense.

On the other hand, Spall and Pickart (2003) present a case for winter wind forcing in the Irminger Sea propagating through to the WGCS due to seasonal stratification patterns and guiding topography. Furthermore, the mean SSH gradient as calculated from altimetry is higher at all sections during the time periods here associated with positive NAO (that is, those occurring 6-18 months after a positive wintertime NAO and when Nuka Arctica data are available).

Although SSH altimetry provides tentative evidence for higher geostrophic velocities associated with positive $\mathrm{NAO}$, direct velocity measurements only support this result in the EGCS and not the WGCS. One possibility is that the WGCS responds to NAO on a different timescale, which could be tested further. NAO is likely too broad of an index to be useful in describing the E/WGCS, however, and it would be more productive to investigate more specific conditions such as wind stress and wind stress curl, hydrographic/water mass properties, and stratification. 


\subsection{Error analysis}

The uncertainties presented here are calculated from the standard error of the mean. Two assumptions in determining the effective degrees of freedom are made, namely that the horizontal and vertical bins are independent, i.e. not correlated. The choice of horizontal bins follows directly from Rossby et al. (2017). Further refinements could include increasing the width of the horizontal bin. We note that additional years of Nuka Arctica data are now available: future studies will likely benefit from increased horizontal data coverage and higher degrees of freedom across the width of the current.

\section{Conclusions}

The study used upper-ocean velocity data acquired from an ADCP mounted on the hull of the container ship Nuka Arctica. The ship traverses a route from Denmark to Greenland via the Irminger Sea before rounding Cape Farewell to continue north along the Greenland coast. Upper-ocean transport in the narrow E/WGCS was determined along six sections, two along the eastern side of Greenland and four along the west side of Greenland.

Sections A and F were found to have the highest volume transport. This confirms some form of retroflection/recirculation in the vicinity of Eirik Ridge, but transport loss occurs upstream of where it has been previously observed. The recovery of transport at Section F is directly related to the current core shifting offshore of the shelf break, but the influence of the nearby eddy kinetic energy maximum should be investigated.

The EGCS was found to have a more extreme response to both seasonal variability and North Atlantic Oscillation during the time periods measured. Sea surface height altimetry gradients calculated at all sections indicate that the WGCS may actually have a seasonal cycle of similar magnitude to the EGCS which is not detected when using April - September and October - March as summer and winter since WGCS maximum velocities likely occur earlier in the year as found by Rykova et al. (2015). A similar shifted response time may also be found with NAO, although it would be more fruitful 
for future studies to look at specific, local conditions. These differing responses, as well as the transport loss at Cape Farewell and Eirik Ridge, confirm the existence of two separate recirculation gyres on either side of Greenland.

It is unclear how much of the variability in the WGCS is propagated from the EGCS and how much arises directly from Labrador Sea conditions. Using hydrography to quantify the contribution of different pathways/water masses to the variability on each side of Cape Farewell would likely shed light on this. Another line of future analysis would be to include hydrographic measurements from Argo floats as in Rossby et al. (2017) to obtain full-depth transport estimates. Argo float hydrographic profiles are not available inshore of the $1000 \mathrm{~m}$ isobath and so the hydrographic properties of the coastal current remain sparse; nevertheless this would expand the understanding of water-mass properties along the current system's path. 
$6 \quad$ Figures

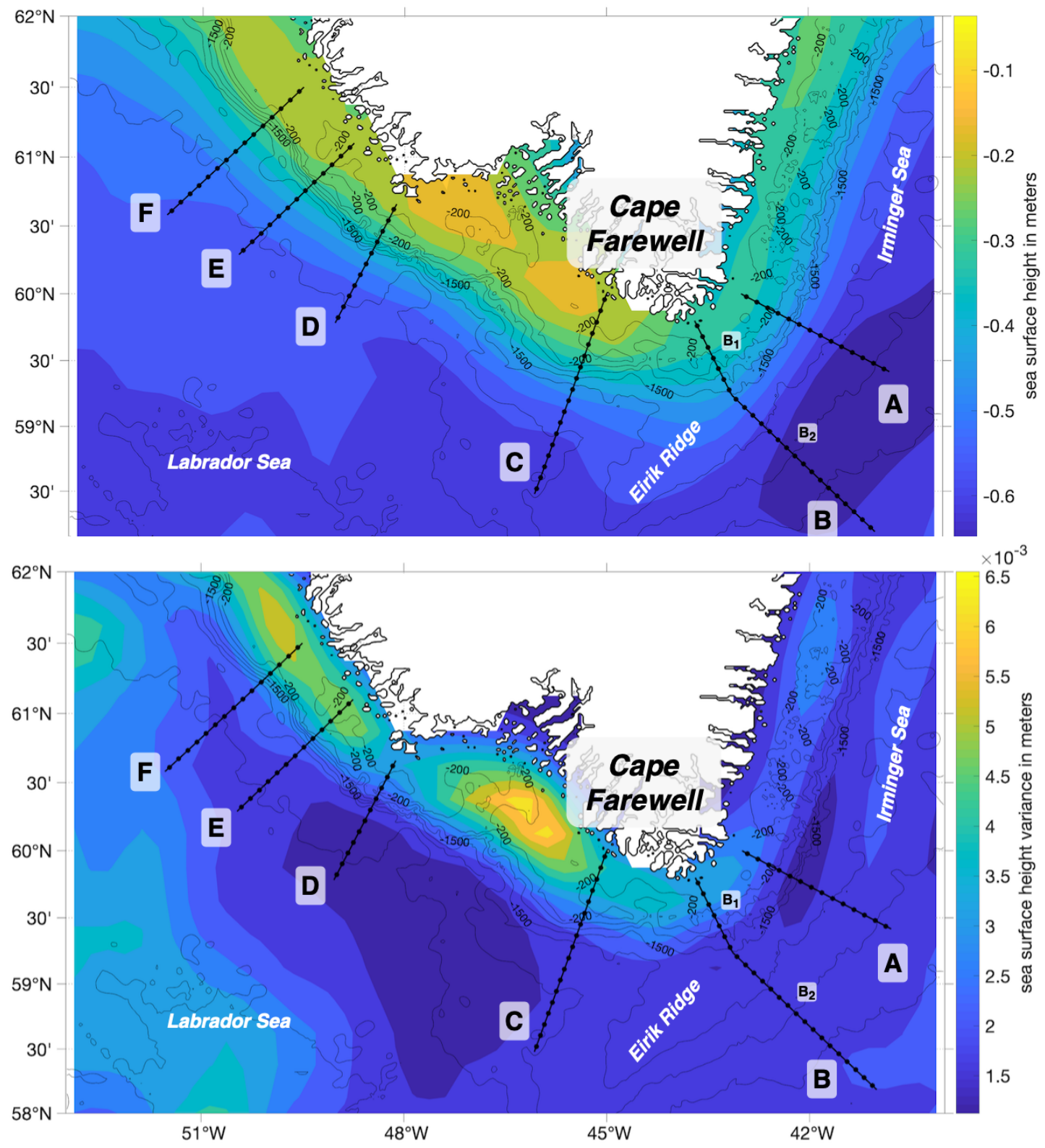

Figure 1.1: Sea Surface Height determined from satellite altimetry, with bathymetry and labeled sections and landmarks. Bathymetry is contoured every $500 \mathrm{~m}$ with the 1500 $\mathrm{m}$ labeled explicitly. The $200 \mathrm{~m}$ isobath is also plotted and labeled. Top Panel: mean sea surface height from 1999-2002 and 2012-2016. Bottom Panel: variance of sea surface height from 1999-2002 and 2012-2016. Altimetry was processed by SSALTO/DUACS and distributed by AVISO+ (https://www.aviso.altimetry.fr) with support from CNES. 


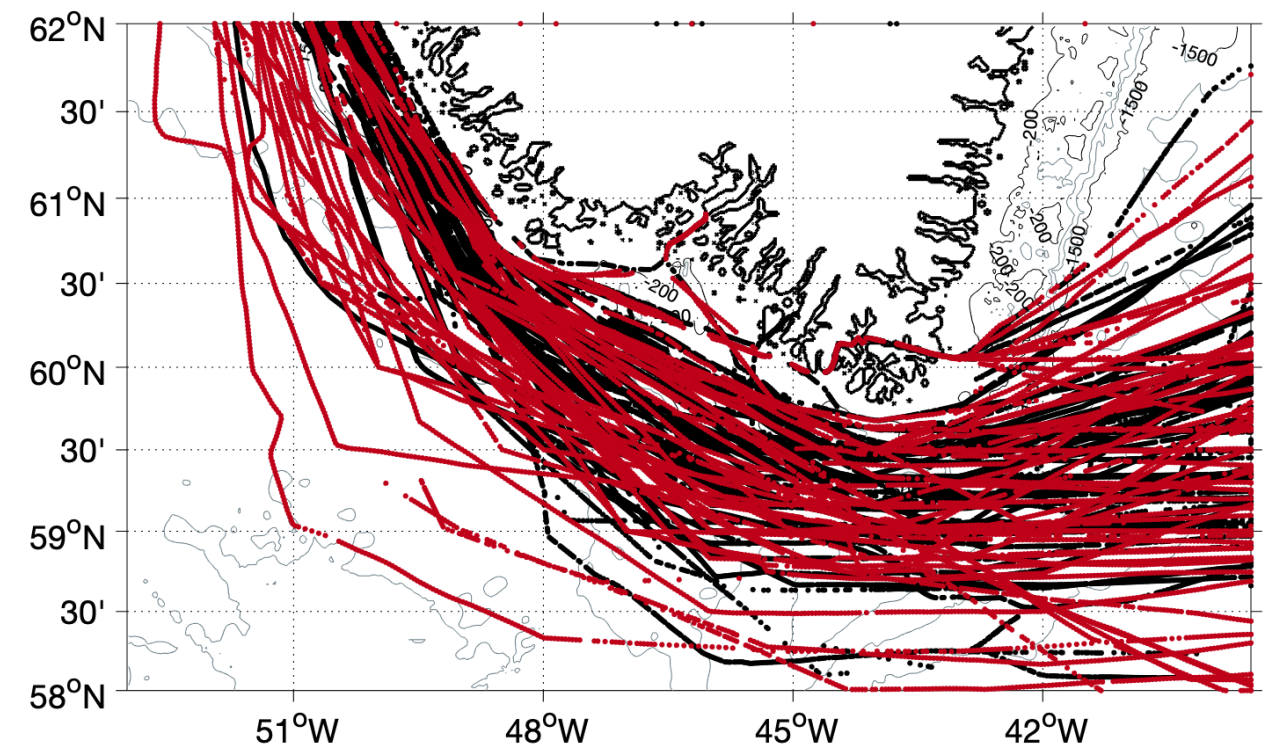

Figure 1.2: All tracks of the Nuka Arctica over the region of interest, 2012-2016 (black) and 1999-2002 (red). 

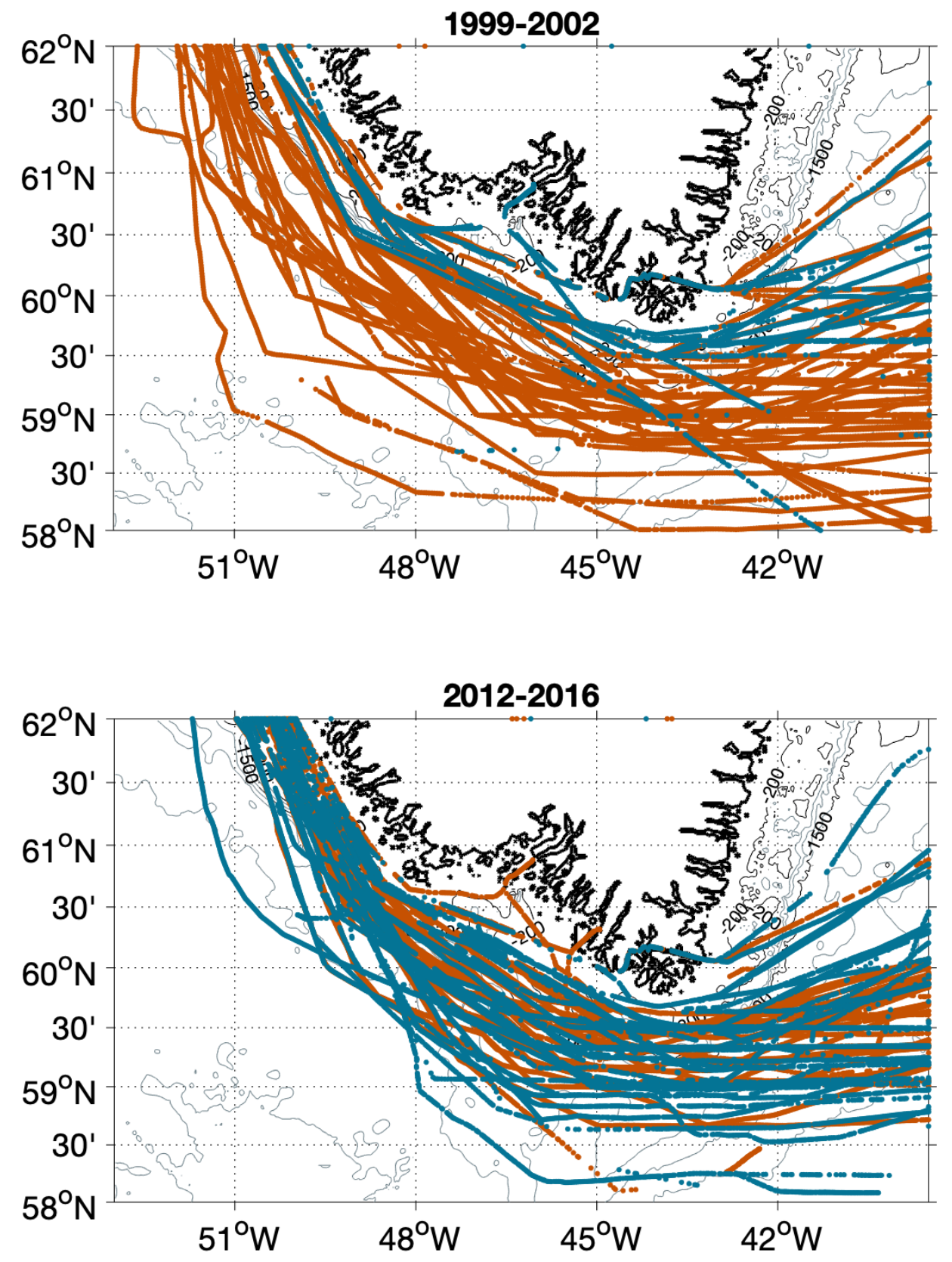

Figure 1.3: Seasonal distribution of Nuka Arctica tracks. Top Panel: 1999-2002. Bottom Panel: 2012-2016. Orange indicates summer (April through September); blue indicates winter (October through March). 


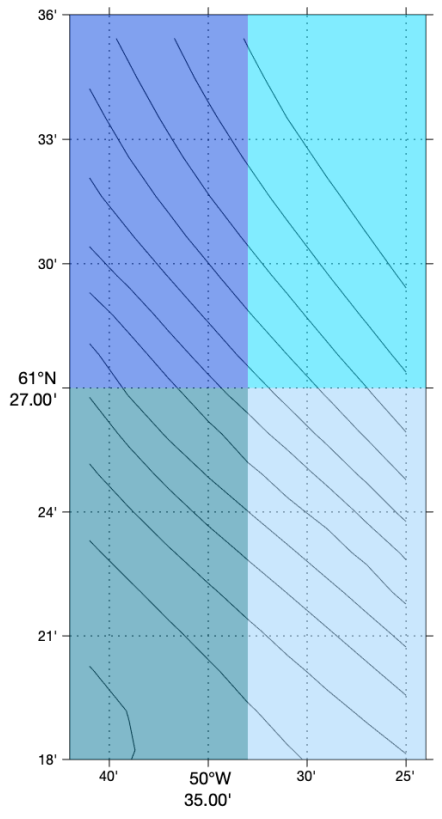

(a)

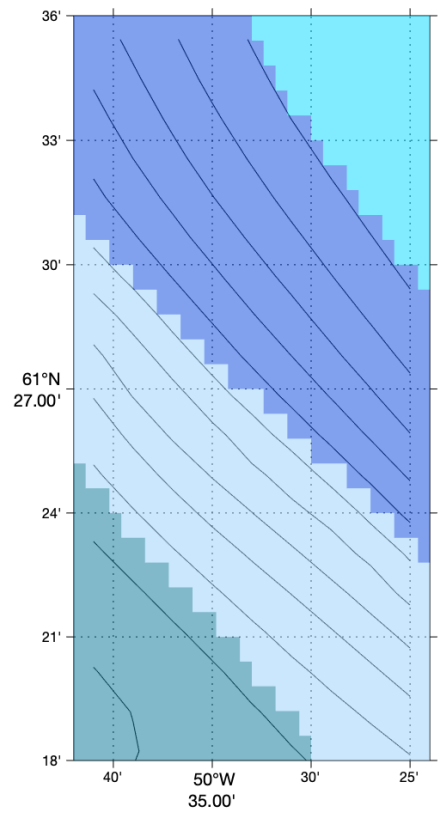

(b)

Figure 1.4: An example of how the effective distance gridding scheme assigns bins. In both (a) and (b), the colors represent the area that is assigned to each adjacent corner. In (a) the grid boxes are unmodified (that is, $\lambda=0$ ). In (b), the effective distance formula described in the text is applied with $\lambda=100 \mathrm{~km}$. Bathymetry contours with $250 \mathrm{~m}$ intervals are underlaid.

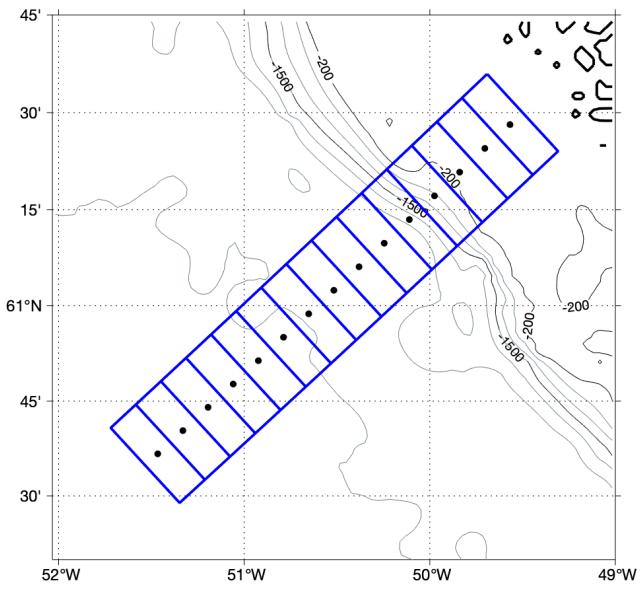

Figure 1.5: An example of the binning scheme used for the cross-sections. Each blue box is $30 \mathrm{~km}$ long in the along-stream direction and $10 \mathrm{~km}$ wide along the section. All measurements located within one of these bins are averaged and assigned to the black midpoint within it. 


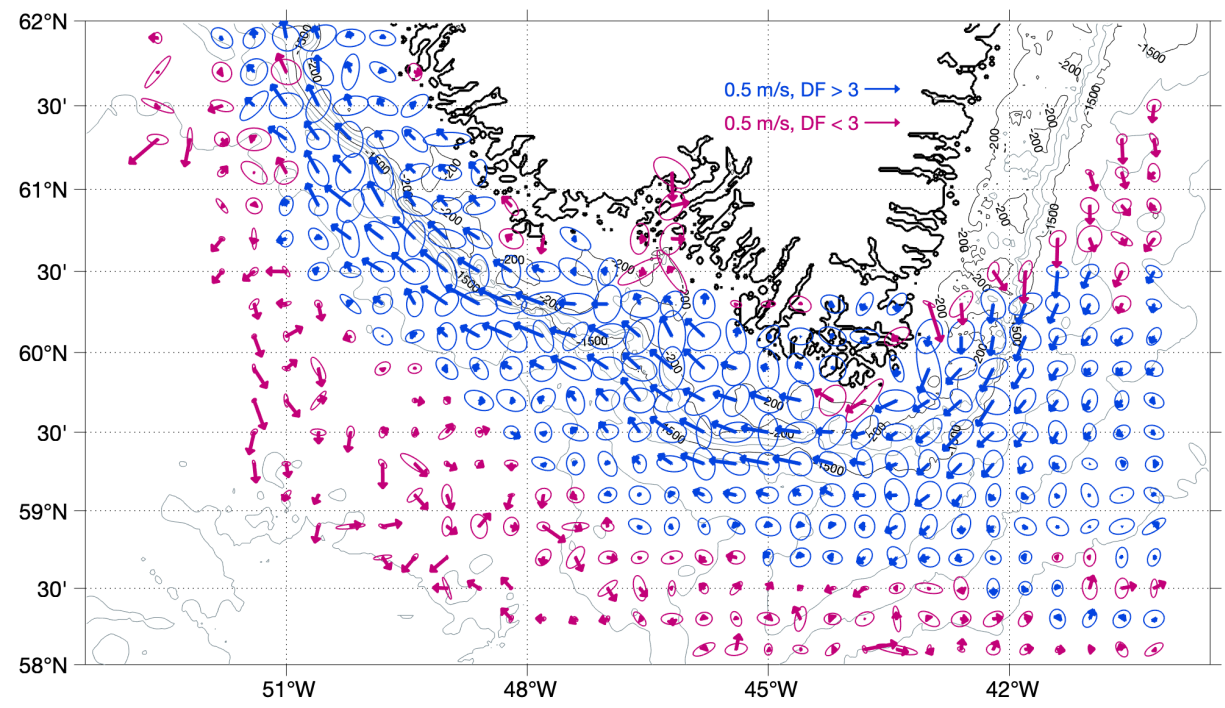

Figure 1.6: Velocities mapped using the effective distance technique described in the text $(\lambda=100 \mathrm{~km})$ and depth-averaged over $100 \mathrm{~m}$. Ellipses represent standard deviations. Vectors and ellipses with more than 3 degrees of freedom ("DF") are colored blue and those with fewer than 3 are colored magenta (where one "degree of freedom" is one ship-crossing). 


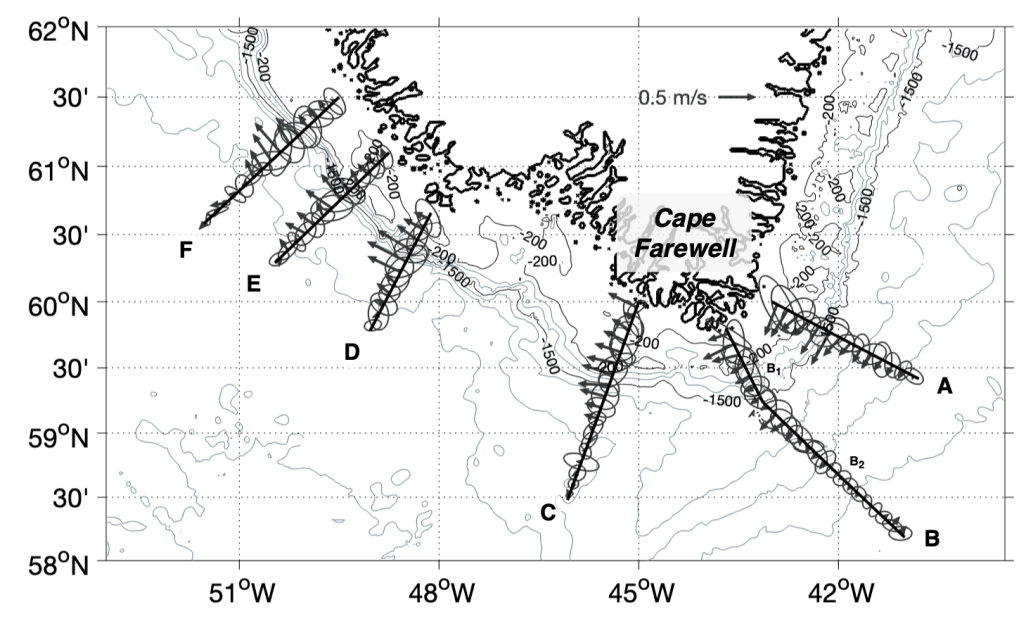

Figure 1.7: Depth-averaged velocities (top $100 \mathrm{~m}$ depth). Vectors underlaid by (top) bathymetry contours and (bottom) mean sea surface height. Satellite bathymetry obtained from Smith and Sandwell (1997). Altimetry was processed by SSALTO/DUACS and distributed by AVISO+ (https://www.aviso.altimetry.fr) with support from CNES. 


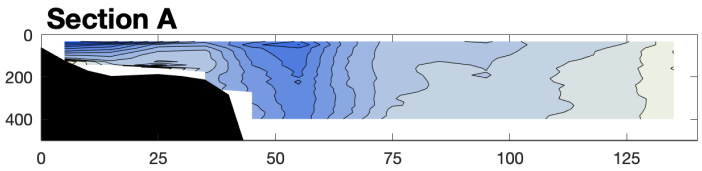

0.6

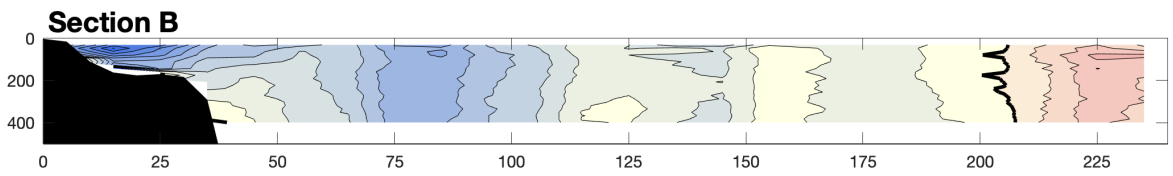

0.4

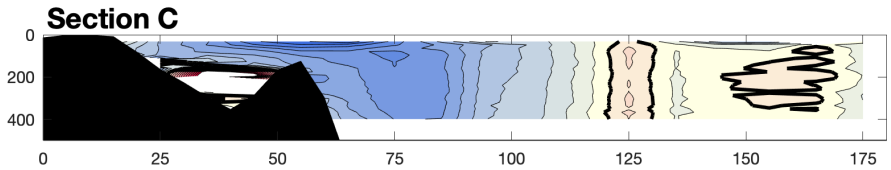

$\hat{\xi}$
흥
$\frac{0}{0}$
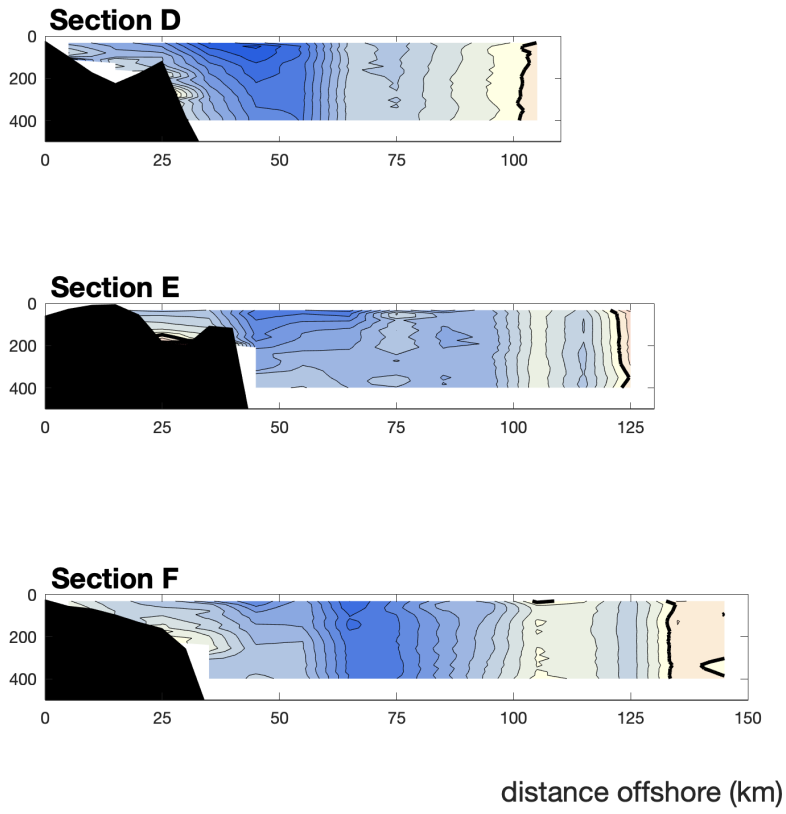

Figure 1.8: Contours of mean along-stream velocity at all sections (labeled). Positive (blue) values represent velocity perpendicular to the section and in the downstream direction. Bathymetry shaded black. Satellite bathymetry obtained from Smith and Sandwell (1997). The zero velocity contour is represented with a thick black line. 
Section A
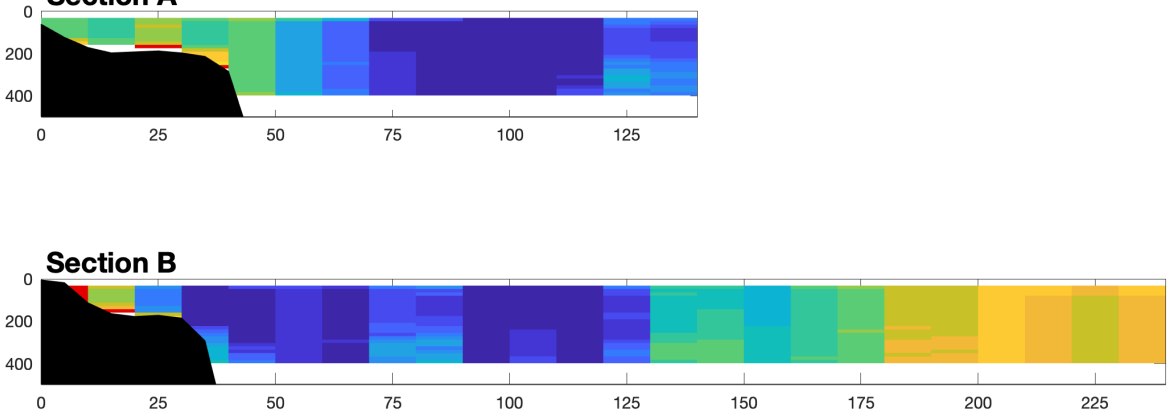

16

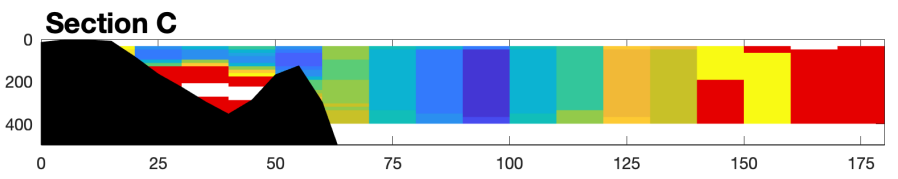

12

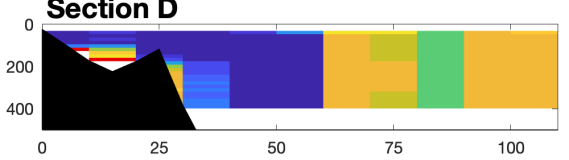

Section E
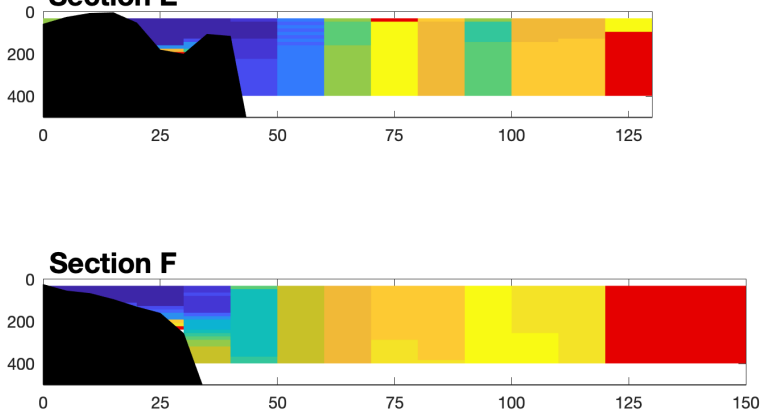

distance offshore $(\mathrm{km})$

Figure 1.9: The degrees of freedom, or the number of ship crossings with good data, in each bin. Note the color scale in which bins with 1-2 degrees of freedom are shaded red, bins with 3 are shaded yellow, and the rest are shaded on a scale from 4-20+. Bathymetry is shaded black. Satellite bathymetry obtained from Smith and Sandwell (1997). 


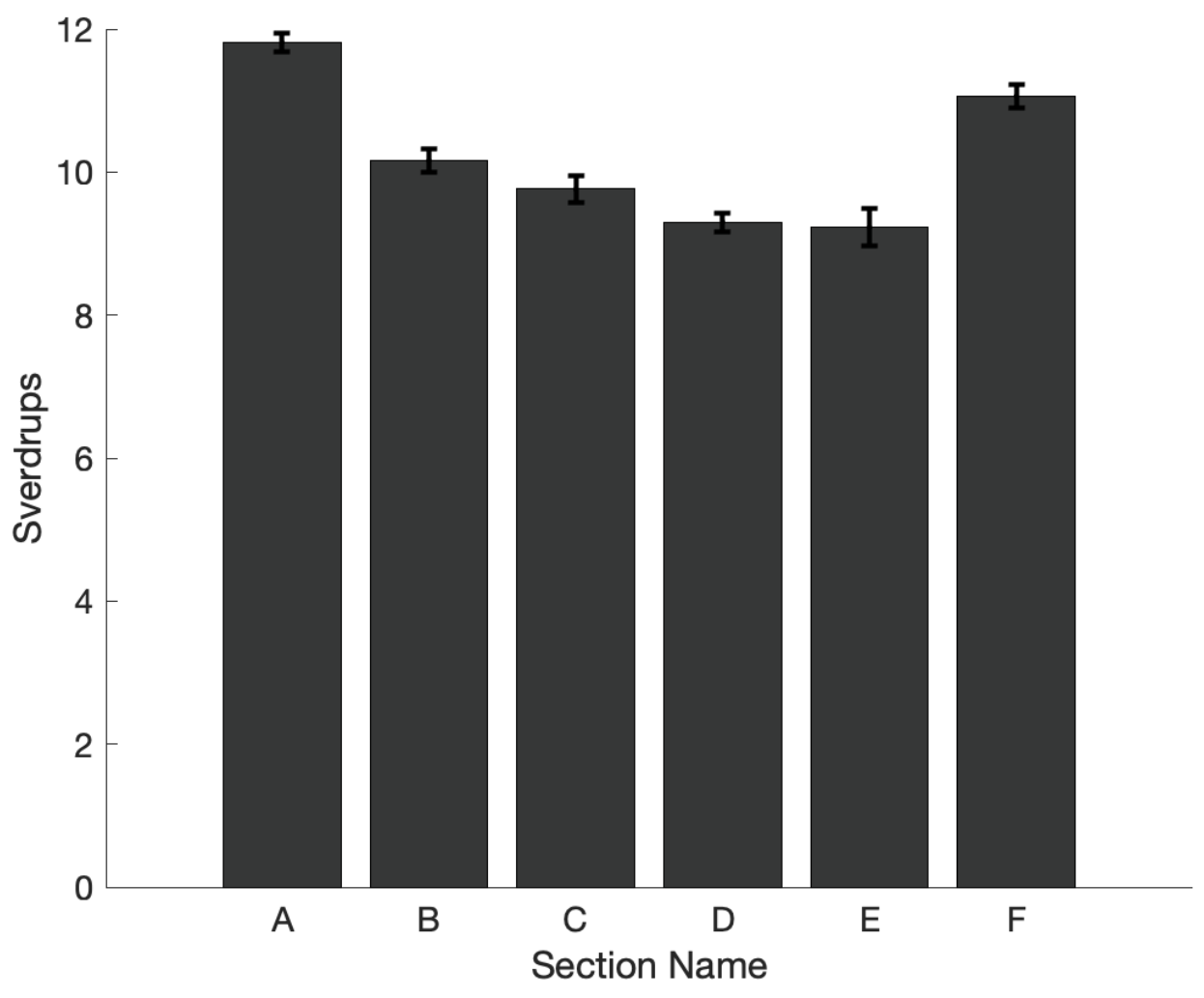

Figure 1.10: Total transport at all sections between 0 to $407 \mathrm{~m}$ depth. At sections with offshore negative flow, the total transport plotted here is the maximum cumulative value. 

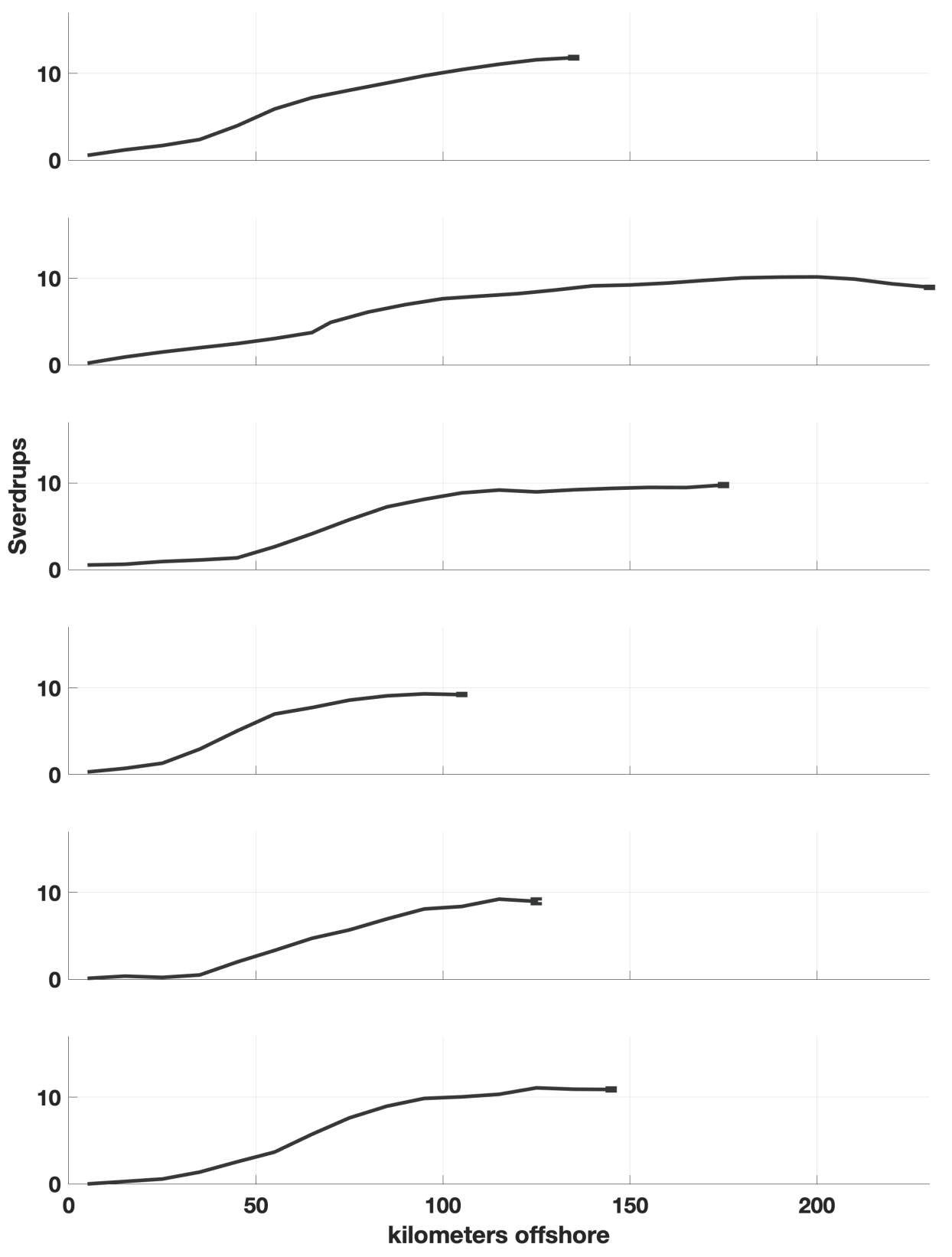

Figure 1.11: Cumulative transport at all sections, in $\mathrm{Sv}$, relative to the endpoint of the section closest to shore. Section A is the topmost panel, Section F is the bottommost panel. Positive transport represents flow in the direction of the current. Error bars represent standard error of the mean in which the degrees of freedom for each bin is the number of ship tracks with usable data. The error for each bin is then propagated through the transport calculation. 


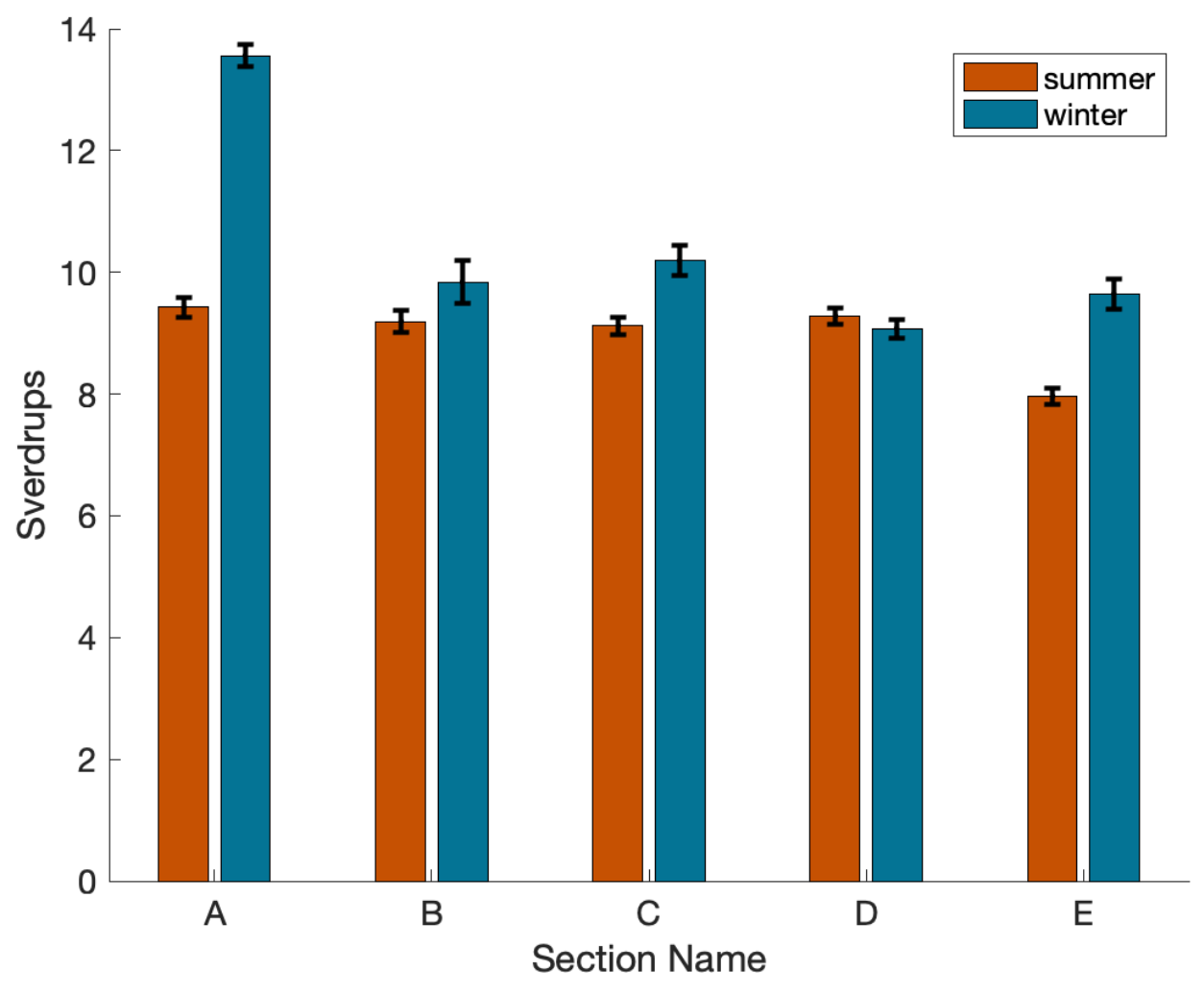

Figure 1.12: Total transport at Sections A through D, during summer (orange) and winter (blue). Summer is defined as April through September and winter is October through March. Error bars as described in Figure 1.11. 

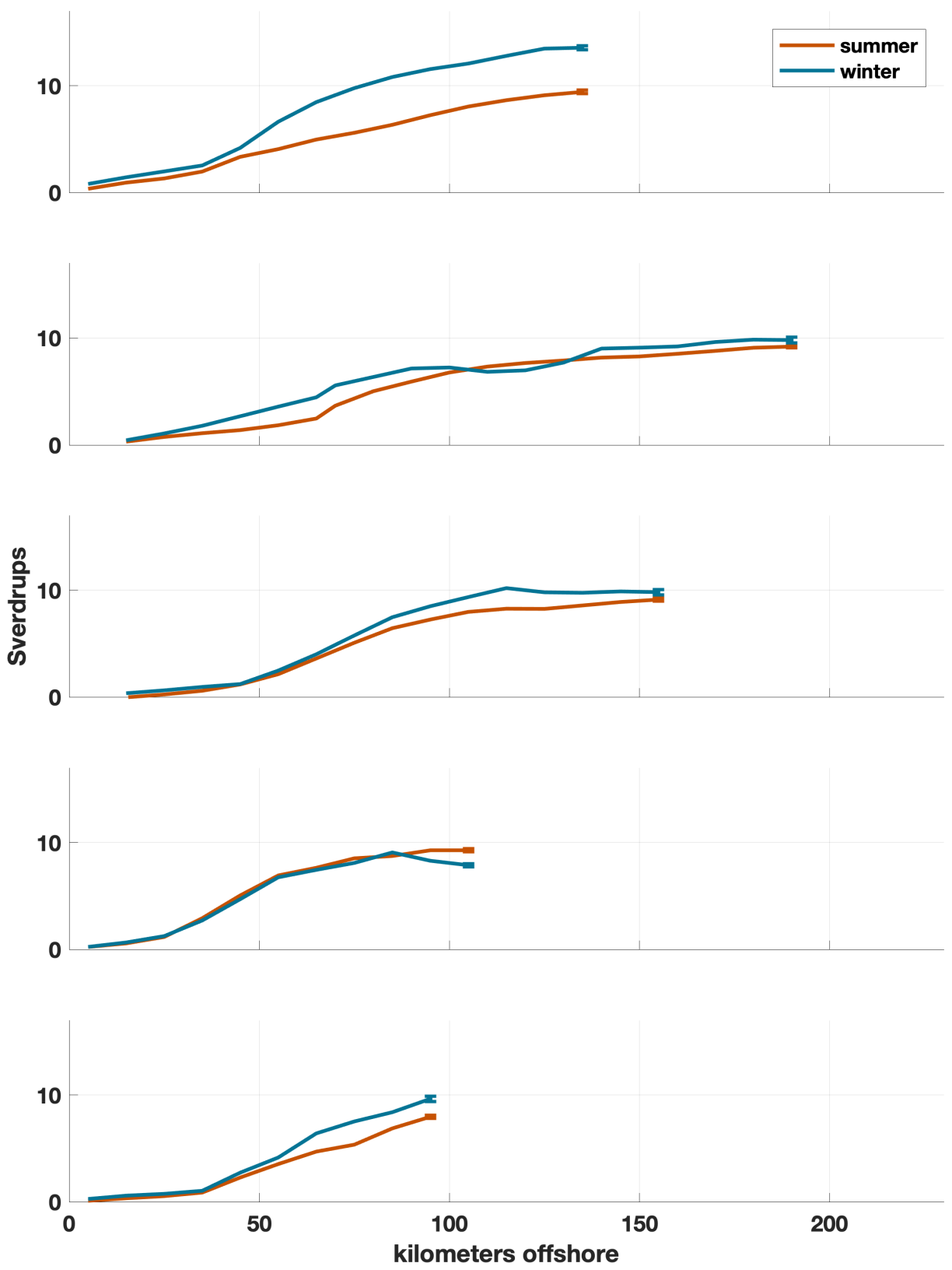

Figure 1.13: Summer (orange) and winter (blue) cumulative transport for Sections A through E (top to bottom). Summer is defined as April through September; Winter is defined as October through March. Positive transport represents flow in the direction of the current. The horizontal axis is the same as in Figure 1.11 even though Sections B and $\mathrm{C}$ start further from shore. Error bars as described in Figure 1.10. 

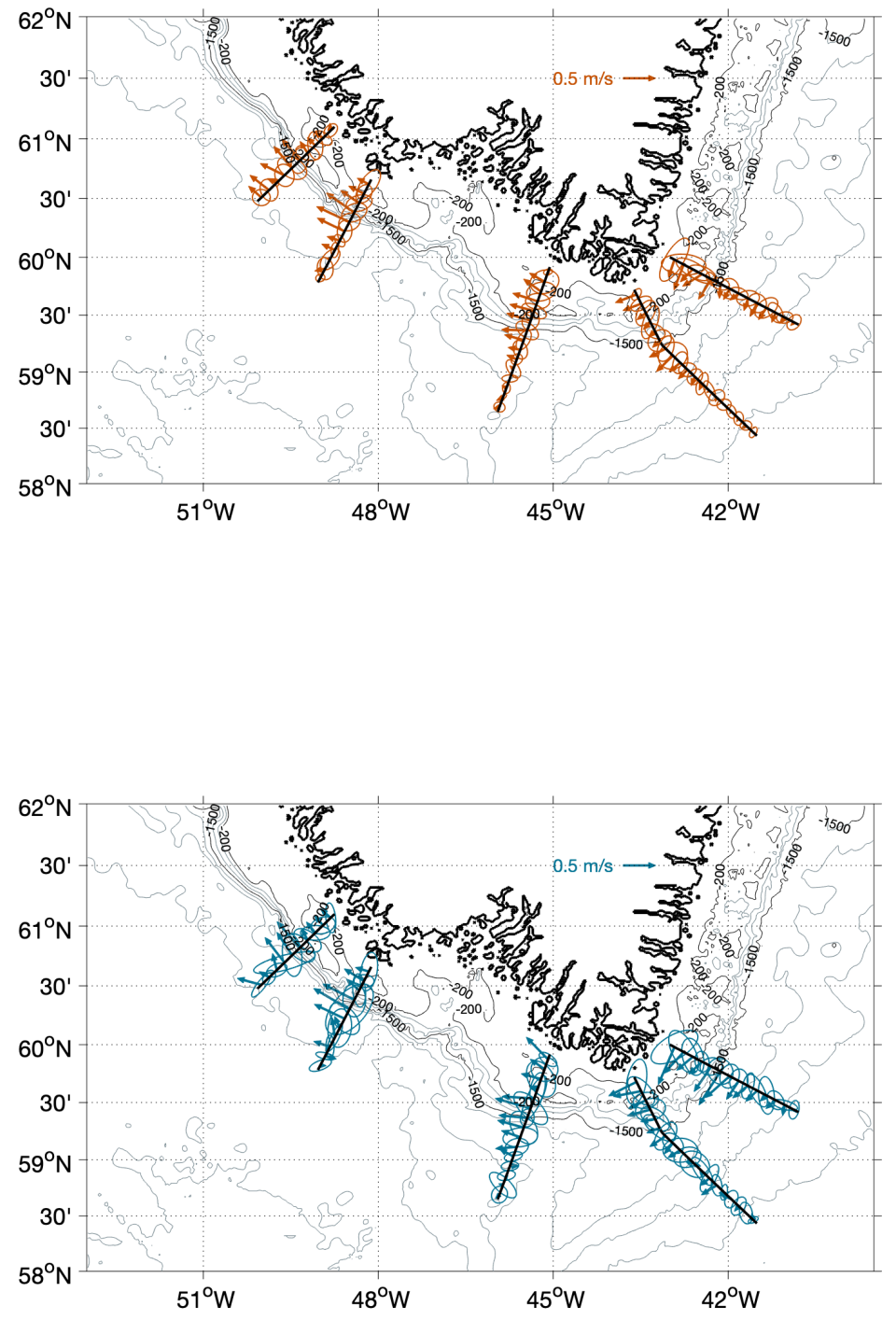

Figure 1.14: Summer (top) and winter (bottom) velocities at Sections A through D, depth-averaged over $100 \mathrm{~m}$ or to the deepest measurement in shallow regions, with bathymetry contours underlaid. Ellipses represent standard deviation. Summer is defined as April through September and winter is October through March. Satellite bathymetry obtained from Smith and Sandwell (1997). 


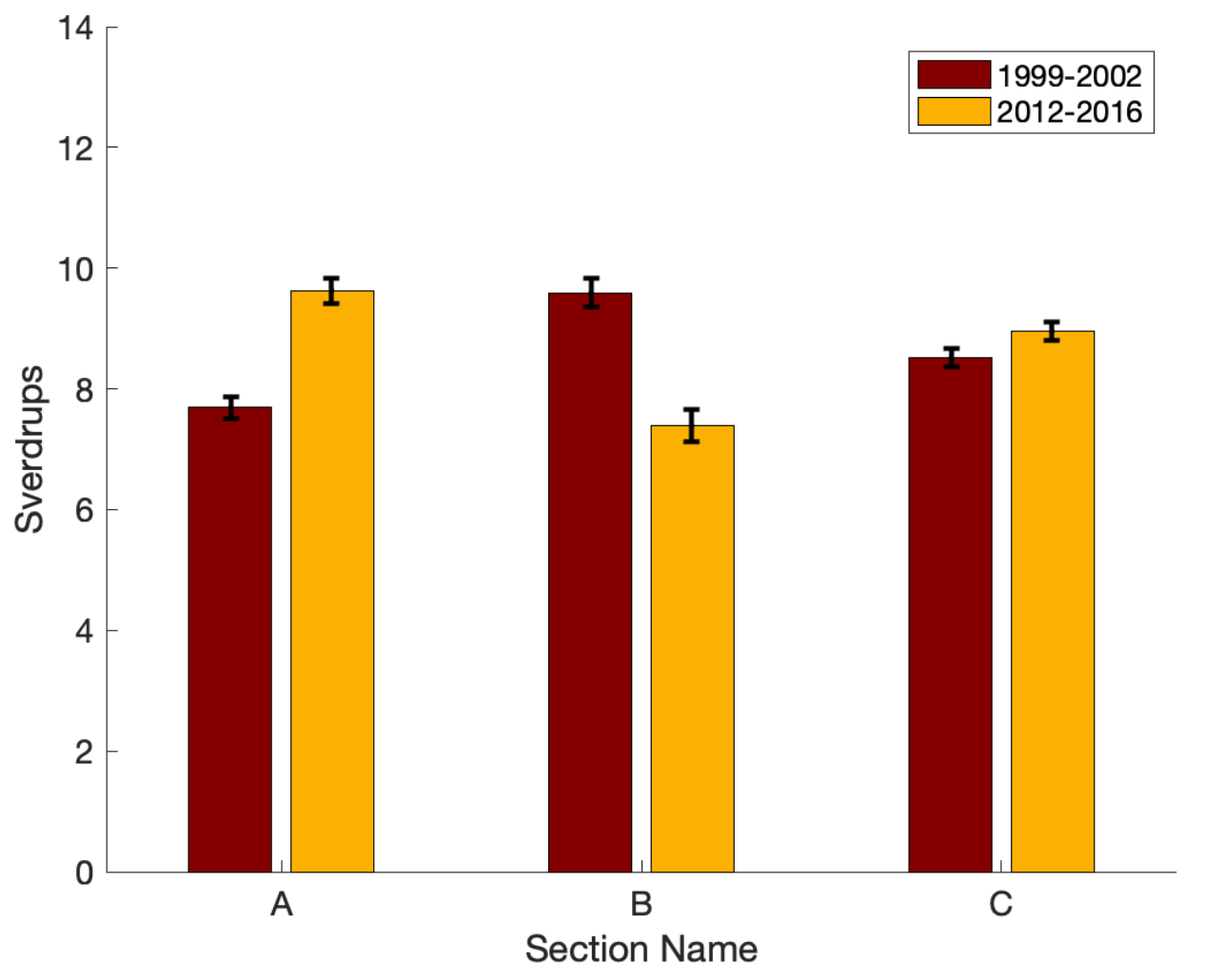

Figure 1.15: Total transport at Sections A through C during summer 1999-2002 (red) and summer 2012-2016 (yellow). Error bars as described in Figure 1.10. 

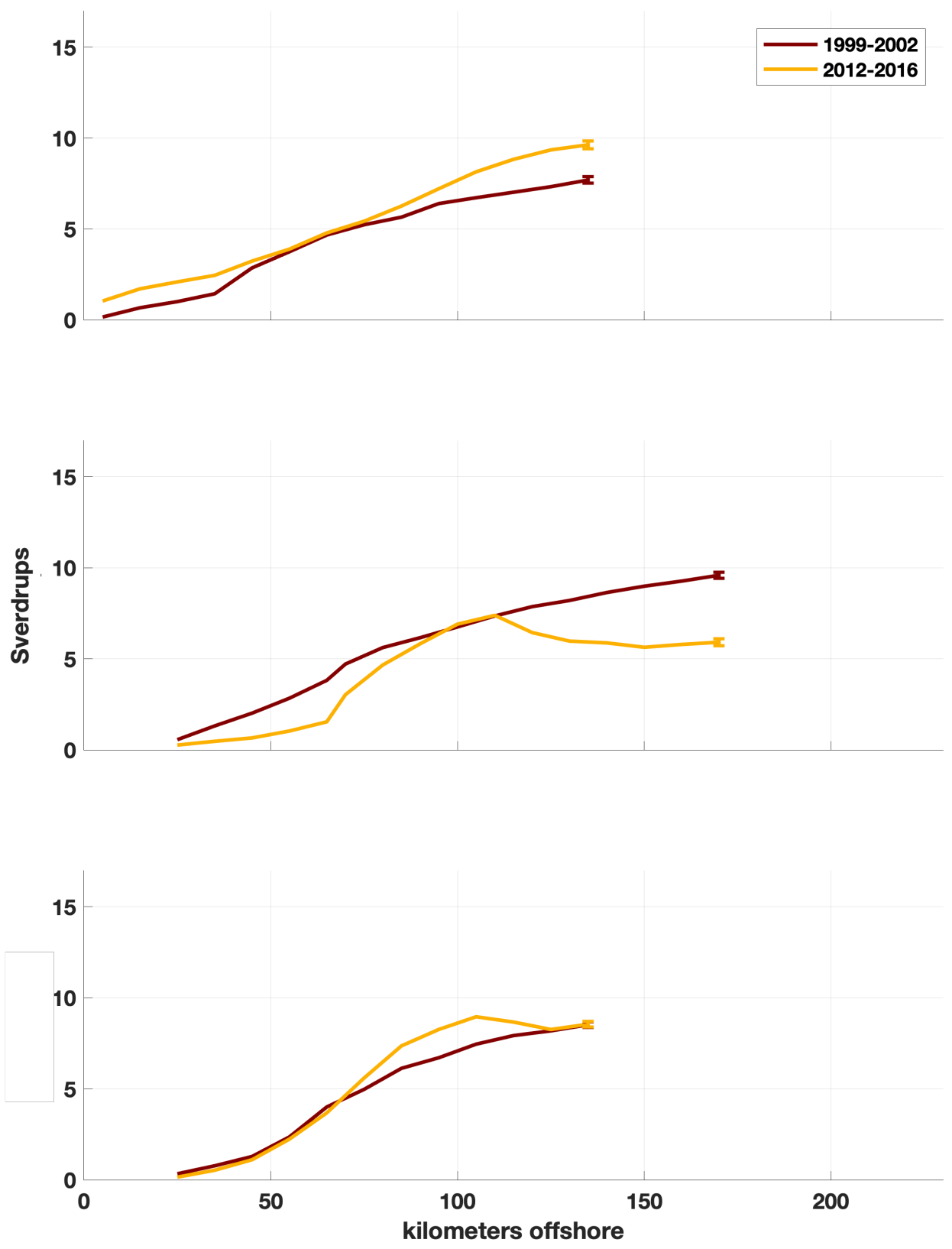

Figure 1.16: 1999 (red) and 2012-2016 (yellow) cumulative transport at Sections A through $\mathrm{C}$ (top to bottom). Positive transport represents flow in the direction of the current. The horizontal axis is the same as in Figure 1.11, though Sections B and C start further from shore. Error bars as described in Figure 1.10. 

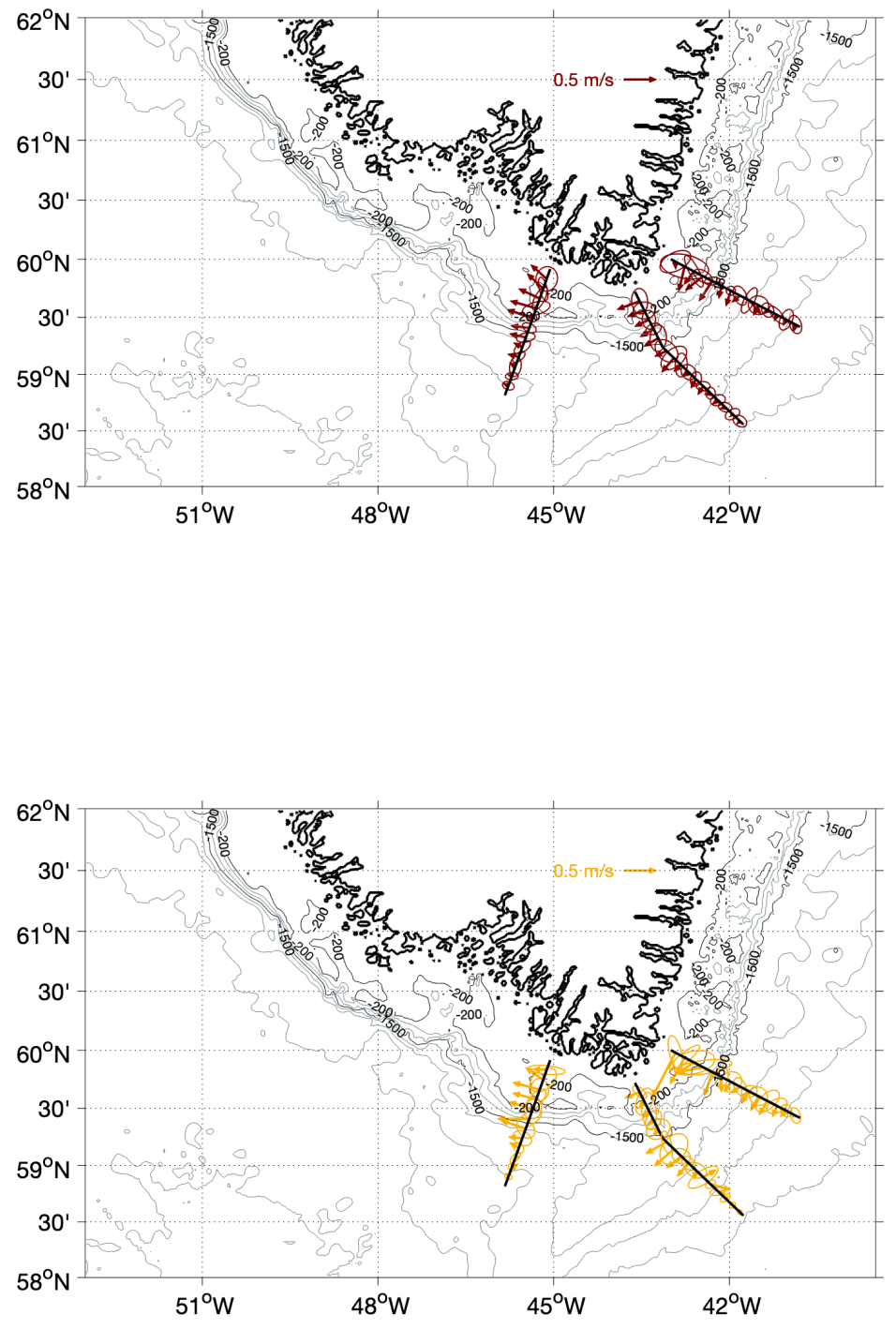

Figure 1.17: 1999-2002(top) and 2012-2016 (bottom) velocities at Sections A through $\mathrm{C}$, depth-averaged over $100 \mathrm{~m}$ or to the deepest measurement in shallow regions, with bathymetry contours underlaid. Ellipses represent standard deviation. Satellite bathymetry obtained from Smith and Sandwell (1997). 


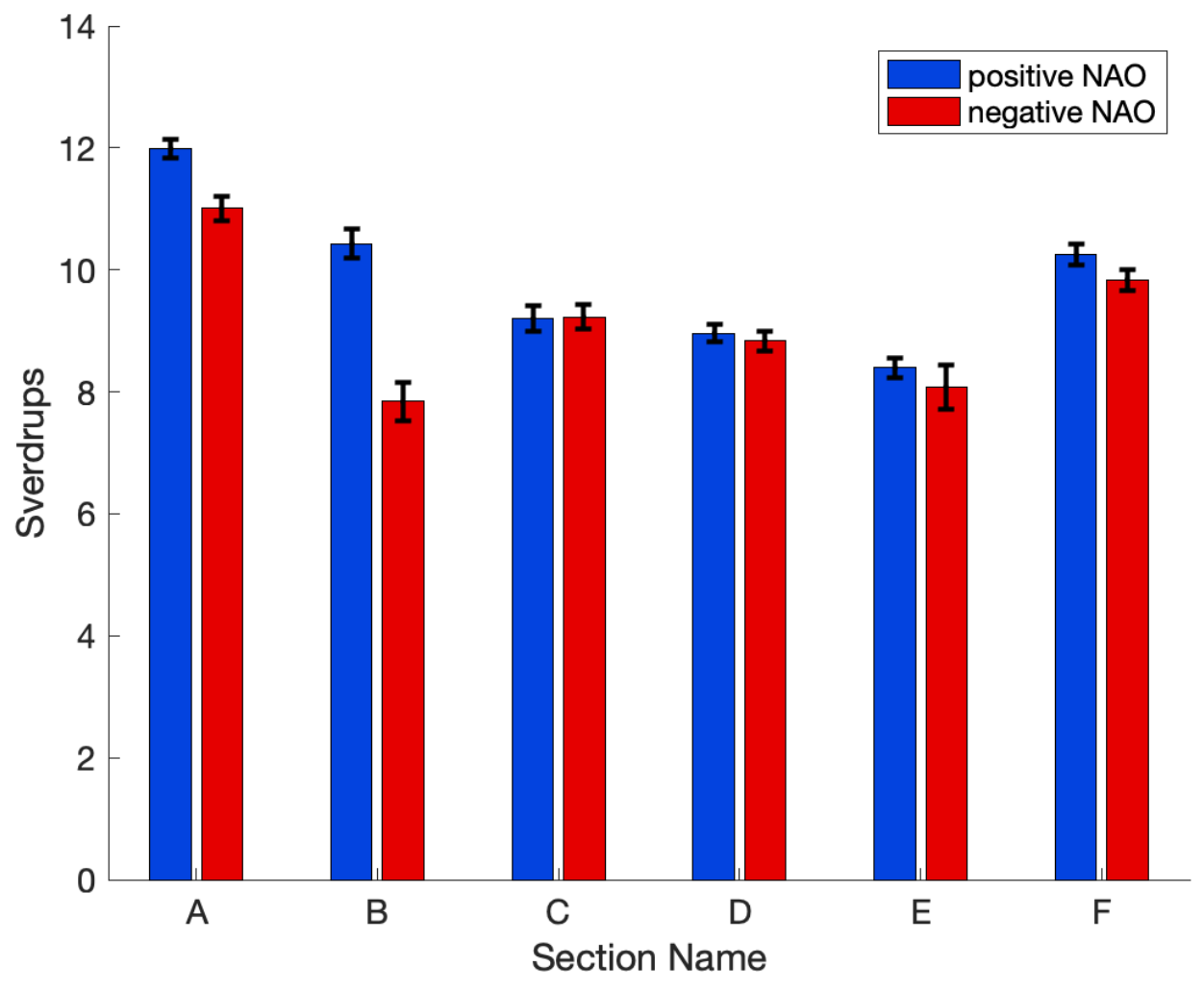

Figure 1.18: Total transport at Sections A through E averaged in periods 6 to 18 months following a positive wintertime NAO in blue and a negative wintertime NAO in red. Error bars as described in Figure 1.10. 

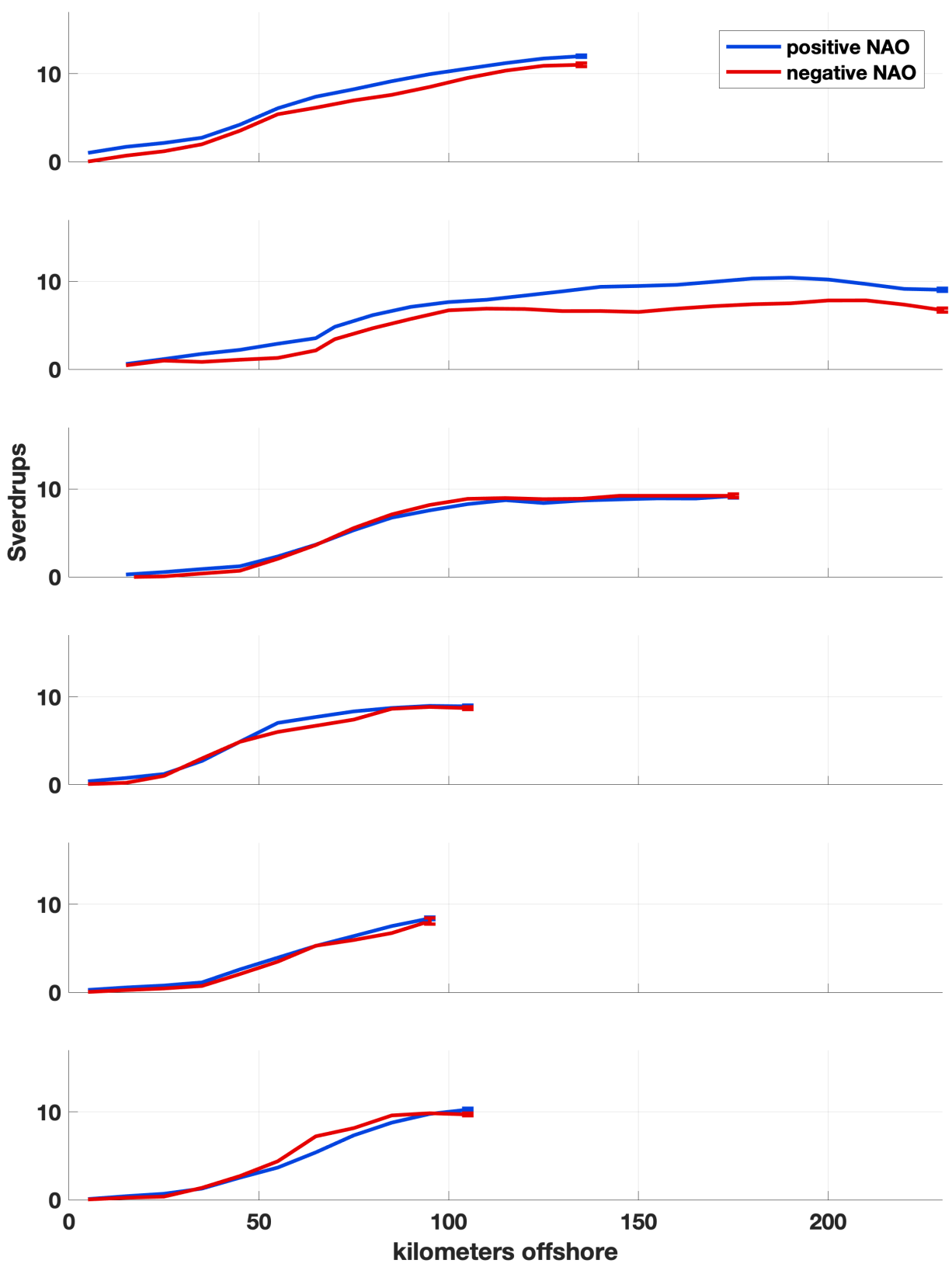

Figure 1.19: Cumulative transport following both positive and negative wintertime at NAO for all section. Section A is the topmost panel; Section F is the bottommost panel. Positive transport is in the direction of the current. Error bars are as described in Figure 1.10 

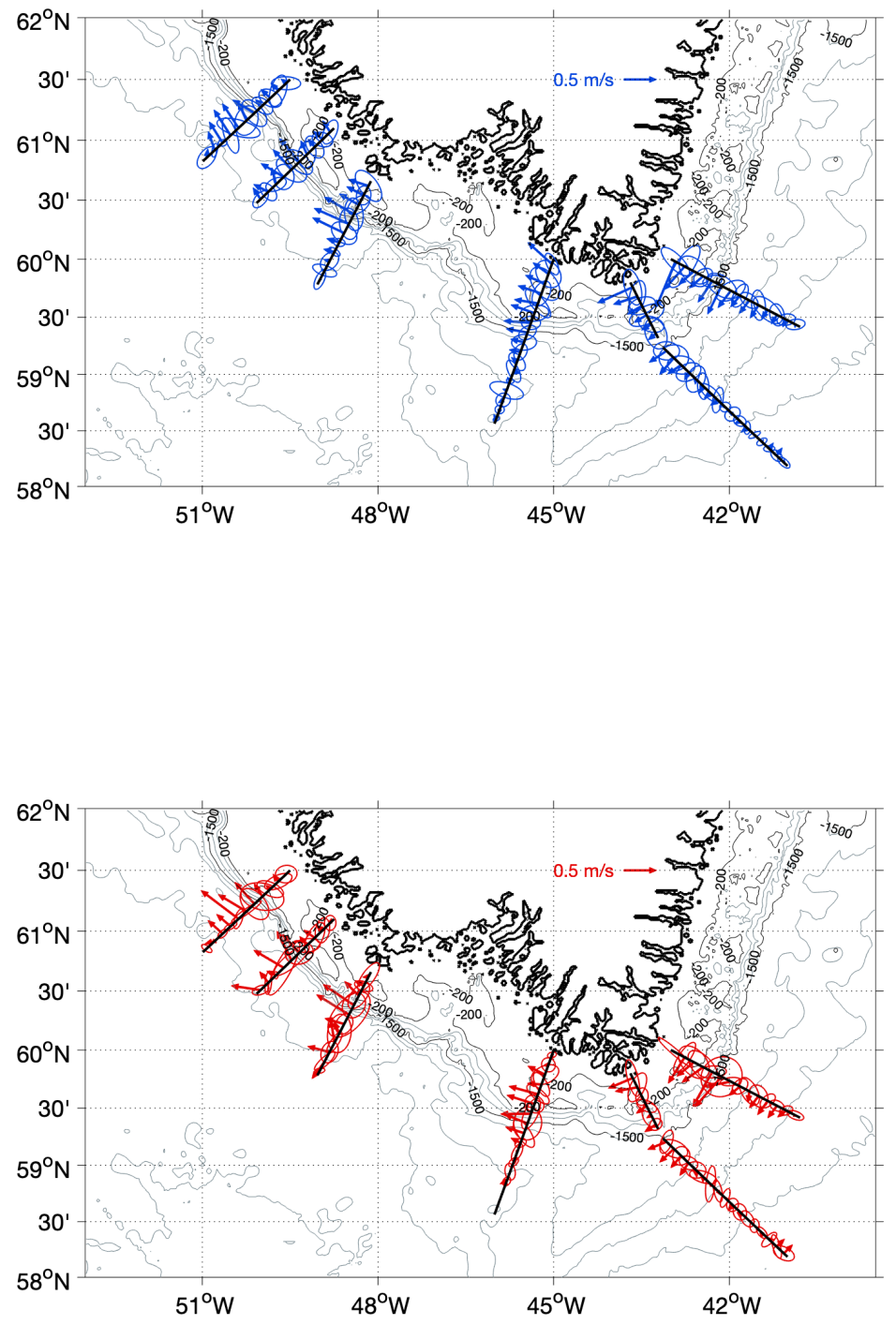

Figure 1.20: Positive NAO (top) and negative NAO (bottom) velocities at Sections A through E, depth-averaged over $100 \mathrm{~m}$ or to the deepest measurement in shallow regions, with bathymetry contours underlaid. Ellipses represent standard deviation. Satellite bathymetry obtained from Smith and Sandwell (1997). 


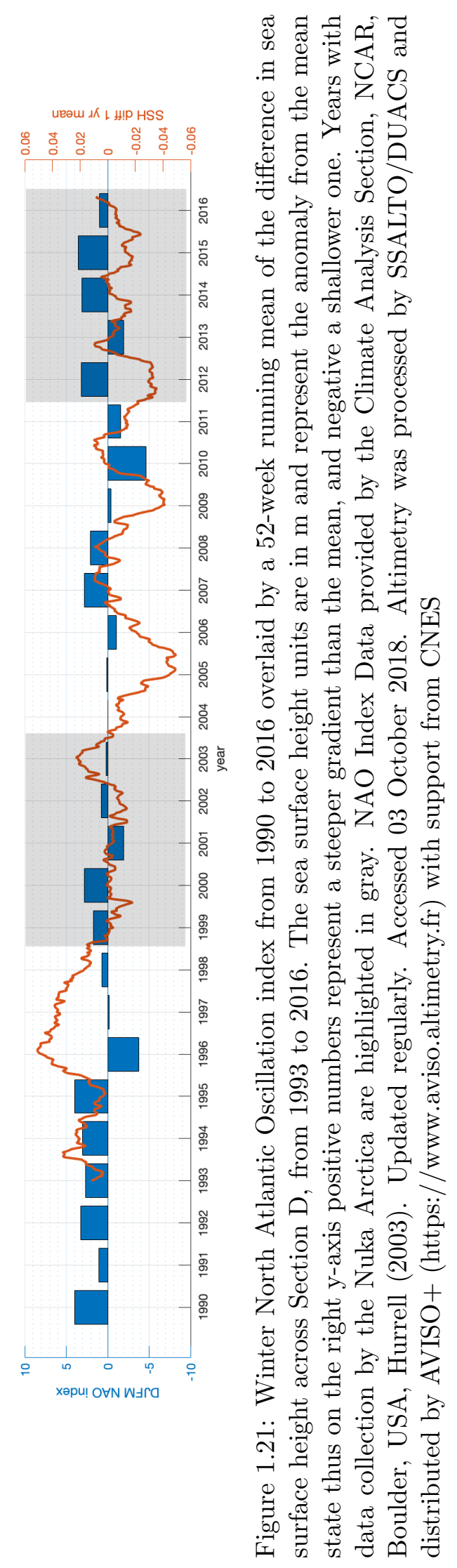




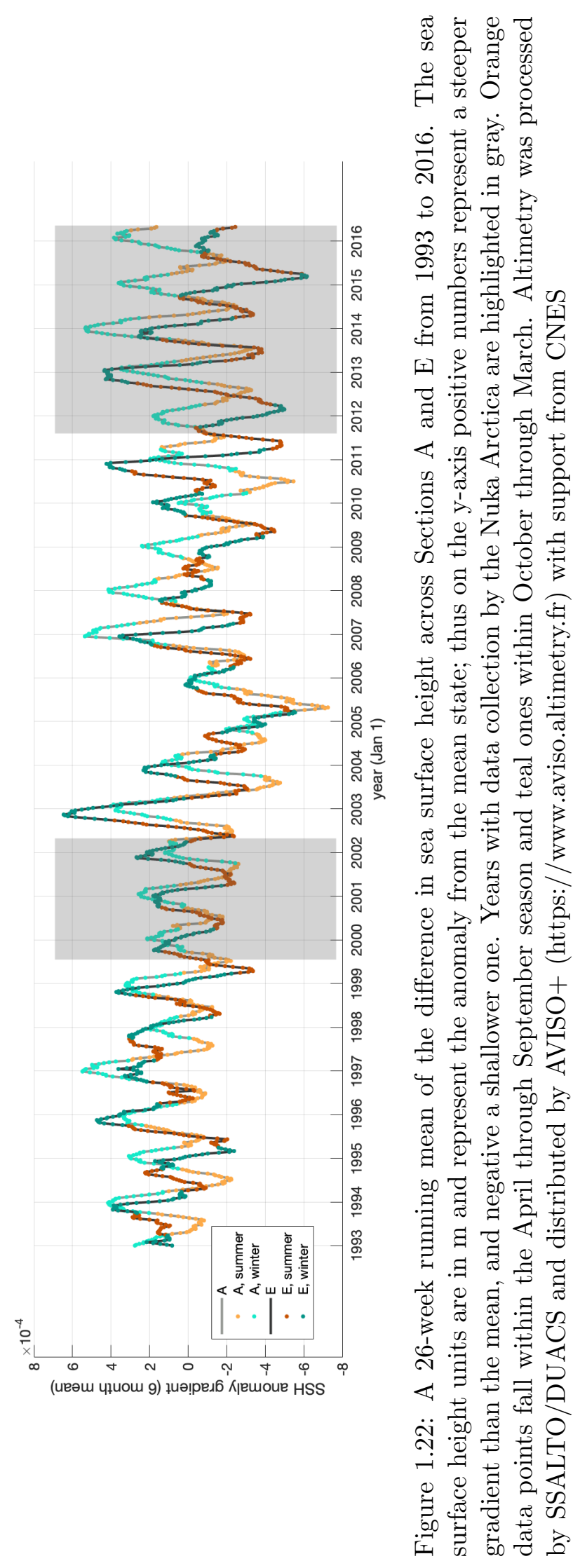




\section{REFERENCES}

Bacon, S., A. Marshall, N. P. Holliday, Y. Aksenov, and S. R. Dye

2014. Seasonal variability of the East Greenland Coastal Current. Journal of Geophysical Research: Oceans, 119(6):3967-3987.

Bacon, S., G. Reverdin, I. G. Rigor, and H. M. Snaith

2002. A freshwater jet on the east Greenland shelf. Journal of Geophysical Research: Oceans, 107(C7).

Brandt, P., F. A. Schott, A. Funk, and C. S. Martins

2004. Seasonal to interannual variability of the eddy field in the Labrador Sea from satellite altimetry. Journal of Geophysical Research: Oceans, 109(C2).

Chafik, L., T. Rossby, and C. Schrum

2014. On the spatial structure and temporal variability of poleward transport between Scotland and Greenland. Journal of Geophysical Research: Oceans, 119(2):824-841.

Chanut, J., B. Barnier, W. Large, L. Debreu, T. Penduff, J. M. Molines, and P. Mathiot 2008. Mesoscale Eddies in the Labrador Sea and Their Contribution to Convection and Restratification. Journal of Physical Oceanography, 38(8):1617-1643.

Cuny, J., P. Rhines, P. Niiler, and S. Bacon

2002. Labrador Sea Boundary Currents and the Fate of the Irminger Sea Water. American Meteorological Society, 32:627-647.

Curry, R., M. McCartney, and T. Joyce

1998. Oceanic transport of subpolar climate signals to mid-depth subtropical waters. Nature, 391:575-577.

Daniault, N., H. Mercier, and P. Lherminier 
2011. The 1992-2009 transport variability of the East Greenland-Irminger Current at $60^{\circ}$ N. Geophysical Research Letters, 38.

De Jong, M. F., A. Bower, and H. Furey

2016. Seasonal and inter-annual variations of Irminger Ring formation and boundaryinterior heat exchange in FLAME. Journal of Physical Oceanography, 46:1717-1734.

Flatau, M. K., L. Talley, and P. P. Niiler

2003. The North Atlantic Oscillation, Surface Current Velocities, and SST Changes in the Subpolar North Atlantic. Journal of Climate, 16(14):2355-2369.

Fratantoni, P. and R. S. Pickart

2007. The Western North Atlantic Shelfbreak Current System in Summer. Journal of Physical Oceanography, 37(10):2509-2533.

Georgiou, S., C. G. van der Boog, N. Brüggemann, S. L. Ypma, J. D. Pietrzak, and C. A. Katsman

2019. On the interplay between downwelling, deep convection and mesoscale eddies in the Labrador Sea. Ocean Modelling, 135:56-70.

Häkkinen, S. and P. Rhines

2004. Decline of Subpolar North Atlantic Circulation During the 1990s. Science, 304:555-559.

Hall, M., D. Torres, and I. Yashayaev

2013. Absolute velocity along the AR7W section in the Labrador Sea. Deep Sea Research I, 72:72-87.

Holliday, N. P., S. Bacon, J. Allen, and E. L. McDonagh

2009. Circulation and Transport in the Western Boundary Currents at Cape Farewell, Greenland. Journal of Physical Oceanography, 39(8):1854-1870.

Holliday, N. P., A. Meyer, S. Bacon, S. G. Alderson, and B. de Cuevas 
2007. Retroflection of part of the east Greenland current at Cape Farewell. Geophysical Research Letters, 34(7).

Kawasaki, T. and H. Hasumi

2014. Effect of freshwater from the West Greenland Current on the winter deep convection in the Labrador Sea. Ocean Modelling, 75:51-64.

Lavender, K. L., W. B. Owens, and R. E. Davis

2005. The mid-depth circulation of the subpolar North Atlantic Ocean as measured by subsurface floats. Deep Sea Research I, 52:767-785.

Lin, P., R. S. Pickart, D. J. Torres, and A. Pacini

2018. Evolution of the Freshwater Coastal Current at the Southern Tip of Greenland. Journal of Physical Oceanography, 48(9):2127-2140.

Lique, C. and M. D. Thomas

2018. Latitudinal shift of the Atlantic Meridional Overturning Circulation source regions under a warming climate. Nature Climate Change, 8:1013-1020.

Myers, P. G., N. Kulan, and M. H. Ribergaard

2007. Irminger Water variability in the West Greenland Current. Geophysical Research Letters, 34(17).

Prater, M.

2002. Eddies in the Labrador Sea as Observed by Profiling RAFOS Floats and Remote Sensing. American Meteorological Society, 32:411-427.

Rossby, T., G. Reverdin, L. Chafik, and H. Søiland

2017. A direct estimate of poleward volume, heat, and freshwater fluxes at $59.4^{\circ} \mathrm{N}$ between Greenland and Scotland. Journal of Geophysical Research: Oceans, 122:58705887.

Rykova, T., F. Straneo, and A. Bower

2015. Seasonal and interannual variability of the West Greenland Current System in 
the Labrador Sea in 1993-2008. Journal of Geophysical Research: Oceans, 120:13181332.

Sarafanov, A., A. Falina, H. Mercier, A. Sokov, G. Claire, S. Gladyshev, F. Gaillard, and N. Daniault

2012. Mean full-depth summer circulation and transports at the northern periphery of the Atlantic Ocean in the 2000s. Journal of Geophysical Research, 117.

Schmidt, S. and U. Send

2007. Origin and Composition of Seasonal Labrador Sea Freshwater. Journal of Physical Oceanography, 37(6):1445-1454.

Smith, W. T. H. and D. T. Sandwell

1997. Global seafloor topography from satellite altimetry and ship depth soundings. Science, 277:1957-1962.

Spall, M. and R. S. Pickart

2003. Wind-driven recirculations and exchange in the Labrador and Irminger Seas. Journal of Physical Oceanography, 33:1829-1845.

Sutherland, D. A. and R. S. Pickart

2008. The East Greenland Coastal Current: Structure, variability, and forcing. Progress in Oceanography, 78(1):58-77.

Våge, K., R. S. Pickart, A. Sarafanov, Øyvind Knutsen, H. Mercier, P. Lherminier, H. M. van Aken, J. Meincke, D. Quadfasel, and S. Bacon

2011. The Irminger Gyre: Circulation, convection, and interannual variability. Deep Sea Research Part I: Oceanographic Research Papers, 58(5):590 - 614.

Wang, Y.-H., L.-Y. Chiao, K. M. M. Lwiza, and D.-P. Wang 2004. Analysis of flow at the gate of Taiwan Strait. Journal of Geophysical Research, 109(C02025). 
White, M. A. and K. J. Heywood

1995. Seasonal and interannual changes in the North Atlantic subpolar gyre from Geosat and TOPEX/POSEIDON altimetry. Journal of Geophysical Research: Oceans, 100(C12):24931-24941.

Yashayaev, I. and J. W. Loder

2016. Further intensification of deep convection in the Labrador Sea in 2016. Geophysical Research Letters, 44(3):1429-1438.

Zhang, W. and X. Yan

2018. Variability of the Labrador Sea Surface Eddy Kinetic Energy Observed by Altimeter From 1993 to 2012. Journal of Geophysical Research: Oceans, 123(1):601612. 